Illinois State University

ISU ReD: Research and eData

Theses and Dissertations

7-13-2021

\title{
The Pen Is the Sword: Fighting by Writing for Our Future
}

Clinton Alexander Soper

Illinois State University, clintsoper@yahoo.com

Follow this and additional works at: https://ir.library.illinoisstate.edu/etd

\section{Recommended Citation}

Soper, Clinton Alexander, "The Pen Is the Sword: Fighting by Writing for Our Future" (2021). Theses and Dissertations. 1473.

https://ir.library.illinoisstate.edu/etd/1473

This Thesis is brought to you for free and open access by ISU ReD: Research and eData. It has been accepted for inclusion in Theses and Dissertations by an authorized administrator of ISU ReD: Research and eData. For more information, please contact ISUReD@ilstu.edu. 


\section{THE PEN IS THE SWORD: FIGHTING BY WRITING FOR OUR FUTURE}

\section{CLINTON SOPER}

\section{Pages}

Suffering from a personal crisis of passivity in his teaching of writing and personal composition in the public sphere, Soper looks for inspiration and guidance through a multidisciplinary and transdisciplinary inquiry into the disciplines of composition, teaching high school English Language Arts, and practicing Kendo, the Japanese Way of the Sword. Soper reflects not only on his personal crisis borne of the socio-political landscape of the current moment but calls for and promotes a redemption of our public discourse in the interest of battling our shared exigencies: the dual-crises of trust in our democratic institutions and our global environmental crisis. Soper investigates how he can seize the opportunity to contribute to finding solutions for these various crises by considering the kendo concept of ki-ken-tai-ichi, which is the standard for a successful strike in kendo.

KEYWORDS: Rhetoric, composition, kendo, crisis, project-based learning, English Language Arts 
THE PEN IS THE SWORD: FIGHTING BY WRITING FOR OUR FUTURE

CLINTON SOPER

A Thesis Submitted in Partial

Fulfillment of the requirements

for the Degree of

MASTER OF SCIENCE

Department of English

ILLINOIS STATE UNIVERSITY 
(C) 2021 Clinton Soper 
THE PEN IS THE SWORD: FIGHTING BY WRITING FOR OUR FUTURE

CLINTON SOPER

COMMITTEE MEMBERS:

Bob Broad, Chair

Julie Jung 


\section{ACKNOWLEDGMENTS}

I owe a debt of gratitude to those who inspired and informed this project. I am forever thankful for the guidance, enthusiasm, and motivation of Dr. Bob Broad, who greatly contributed to the initial inception of this inquiry after experiencing my kendo demonstration at the Summer Institute of the Illinois State Writing Project. Dr. Broad then shepherded me through this process of writing to learn, and the strides I stand to make as a compositionist and an English teacher from my labor reflected here could not have been possible without Dr. Broad's mentorship. Our working relationship goes back twelve years, to an undergraduate Creative Nonfiction course, and he has been a steady influence in my writing and teaching ever since.

My heartfelt thanks to Dr. Julie Jung, who stepped up and offered her time, energy, and expertise to help me work through not only this thesis but through the challenges of finishing my coursework and this thesis during the stressful times of the past year. Dr. Jung's has supported and been patient with my progress, and her willingness to bear with and help me reach this goal will always be a reminder of how I want to treat my students.

I would not be in the position I am today without the community offered by the Bloomington-Normal Kendo Club. I am forever thankful that I randomly discovered the club's existence in a casual conversation with a student at ISU. The rest is a decade of history. My thanks to Dr. Nobu Tanaka, our fearless leader, for his commitment to our club and to the discipline of kendo. I also want to thank fellow BNKC members who have offered me their time and energy in the dojo, notably Gary Mazzotti, Josh Rhodes, and Dan Walther.

My final thanks is reserved for my wife, Charity, who has been a true partner in life. I could not have accomplished any of this without her unwavering love and support. Words cannot do justice to show how I feel about what she has offered me, so I can only hope that my actions speak for me.

C.S. 


\section{CONTENTS}

ACKNOWLEDGMENTS

Page

FIGURES

CHAPTER I: ATTACKING THE CRISIS 1

Introduction: Danger and Opportunity 1

$\begin{array}{ll}\text { Theoretical Framework: Integrating My Practices } & 7\end{array}$

My Vocation and Location $\quad 9$

Ki-ken-tai-ichi 13

CHAPTER II: KI AND ETHOS 16

Introduction: Summoning the Fighting Spirit 16

$\begin{array}{ll}\text { The Kendo Fighting Spirit } & 17\end{array}$

$\begin{array}{ll}\text { Rei-ho } & 23\end{array}$

$\begin{array}{ll}\text { The Teacher Ethos: Tranquility } & 25\end{array}$

$\begin{array}{ll}\text { Purging the Four Sicknesses } & 30\end{array}$

$\begin{array}{ll}\text { Fear } & 30\end{array}$

$\begin{array}{ll}\text { Doubt } & 31\end{array}$

$\begin{array}{ll}\text { Hesitation } & 33\end{array}$

$\begin{array}{ll}\text { Surprise } & 35\end{array}$

CHAPTER III: KEN AND PEN

Introduction: S(words), the Cutting Edge 38

The Symbolic Power of Sword and Pen $\quad 41$

$\begin{array}{ll}\text { Reverence } & 43\end{array}$

Rhetoric: The Raw Material $\quad 45$

The Life-Giving Sword or the Death-Dealing Sword? $\quad 47$ 
Many Swords: Multimodality, Genre, and the Rhetorical Situation 50

CHAPTER IV: TAI AND ACT 56

Introduction: "One Who Moves Never Grows Cold" 56

$\begin{array}{ll}\text { Practice: The Essential Act } & 58\end{array}$

$\begin{array}{ll}\text { The Three C's } & 60\end{array}$

$\begin{array}{ll}\text { Consistency } & 61\end{array}$

$\begin{array}{ll}\text { Commitment } & 63\end{array}$

$\begin{array}{ll}\text { Communication } & 65\end{array}$

$\begin{array}{ll}\text { Being Present: Demonstrations and Seminars } & 67\end{array}$

$\begin{array}{ll}\text { Growing Through Pain } & 69\end{array}$

$\begin{array}{ll}\text { Coda: Ichi and Integration } & 72\end{array}$

$\begin{array}{ll}\text { REFERENCES } & 78\end{array}$

APPENDIX: PERSONAL PHOTOGRAPHS FROM MY KENDO PRACTICE 80 


\section{FIGURES}

Figure $\quad$ Page

1. St. Louis Japanese cultural festival, Missouri Botanical Garden (2015) 1

2. Bloomington-Normal cultural festival, Miller Park (2011) 11

3. Katana, personal collection (2021) 39

4. Bokken and shinai (2021) 52

5. Kakejiku, Bloomington-Normal Kendo Club (2020) 56

6. Farewell keiko, BNKC (2016) 60

7. Illinois State Writing Project Kendo demo, Fell Arboretum (2018) 67 


\section{CHAPTER I: ATTACKING THE CRISIS}

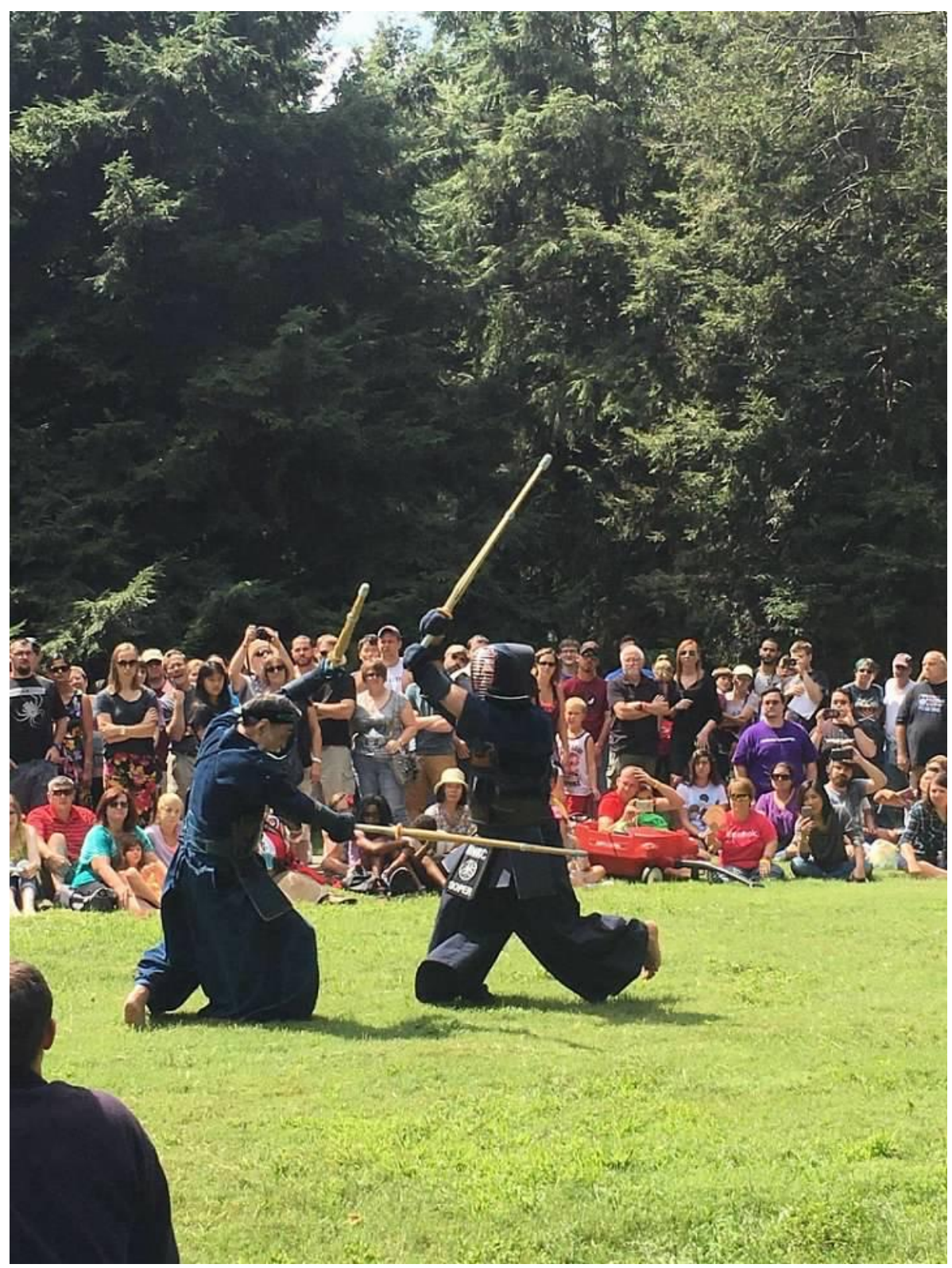

Figure 1: St. Louis Japanese cultural festival, Missouri Botanical Garden (2015)

\section{Introduction: Danger and Opportunity}

I am seeking insight from my unique location at the nexus of studying Rhetoric and

Composition as a graduate student, teaching high school English Language Arts in rural central Illinois, and practicing the Japanese Way of the Sword: Kendo (剣道). Intertwined in my life for 
the past decade, these are three important threads in the fabric of my identity, and I am proud of the effort and time I have dedicated to each endeavor. I am typically a rather self-assured person. Lately, however, l've been wracked by a hollowness.

I have been practicing each discipline with diligence, yet I'm experiencing self-doubt that I will strive to allay by reflecting upon the sources of my self-perceived weakness and discovering fresh inspiration and guidance to invigorate my future. The purpose of this inquiry is to utilize a kendo lens to investigate my misgivings about my writing and teaching practices while also considering how to elevate my kendo with ideas from my experiences in composition studies and teaching writing. I aim for illumination that reveals a fulfilling path forward for each discipline.

I am suffering a crisis of passivity -- of inaction -- as a writer and teacher of writing. As I was taught by Nobu-san at kampai, crisis (危 機) is when "danger" meets "opportunity" in Japanese kanji. The tension inherent in this duality resonates with me, and I use it to introduce my freshmen students to their charitable foundation speech unit and to the study of rhetoric. I explain it thus: Every charitable foundation exists to mitigate or alleviate some kind of crisis. With every crisis there is imminent danger, someone or something needs help, which creates the opportunity for compassionate people and organizations to take action and offer that help. Therefore, a crisis is an opportunity to courageously struggle against a dangerous situation. What danger does my crisis of passivity entail?

The danger I'm facing as a composition teacher in a crisis of passivity is failing to offer my students rich learning experiences. Basically, I'm shying away from the complex, controversial, hotly contested issues of our day for fear of the inquiry devolving into disrespectful, misinformed positions or the intellectual intention being misunderstood and mischaracterized. I'm not challenging my students with writing opportunities that compel them to grapple with our most dire issues. Here are some thesis statements from the exemplification essay that my sophomores finished the year writing: Christmas is the best holiday; summer 
break is better than winter break; giraffes are the best animals; comedy is better than horror (I actually somewhat liked that one); my friends are the best; Titanfall 2 is the best FPS game ever. All of this arguably inconsequential writing I read at the end of last semester is a reflection of my passivity in challenging my students with issues that matter. I wasn't disappointed in my students' lack of seriousness; I was disappointed in myself for not facilitating deeper consideration of various positions on kairotic topics.

The danger unleashed by my passivity as a compositionist is that of demoralized non-participation in discourse after I complete my graduate studies. Where will I write? Where will I express myself? I eschewed social media at its inception, a decision that I must now grapple with, despite my ongoing misgivings about its corrosive effects on long-form reading and the confusion-inducing, reality-bending cacophony of amateur content. Despite my misgivings, I need to explore this outlet as a potential opportunity for my communicative cravings. The crises I'm concerned with don't just pertain to me personally, though.

We're facing crises as a society, too; we're all struggling with a dangerous inability to reach stasis in our most important debates, and the balkanization of our press and media outlets is a major threat to our collaborative problem-solving ability. We're squandering the moment to fight against the degradation of our democratic ideals and institutions and environmental degradation, the dual-crises hovering over us all. I'm beyond frustrated that we cannot even reach stasis to debate, as a body politic, the issue of how to best combat global-warming because we can't even agree that the warming climate is due to human activity. Belief is a spectrum and sovereign citizens' positions on issues can be nuanced, but we're sadly stuck in the deadlock of a bitterly unrelenting and entrenched two-party system that draws a single line in the sand on every issue; the fact that certain dubious positions have become dogma, like trickle down economics or that legacy media organizations cannot be trusted or that abortion is murder, creates a reality in which the two political parties -- the only two we have to choose from -- are in such dire opposition that sheer defiance and demonization 
prevail. It's a dangerous world in which one's fellow citizens are considered an evil enemy. I fear that's increasingly our situation for the politically aware among us.

The opportunity that this American crisis of good faith deliberation offers is a chance to attack my personal weakness that metastasizes as avoiding debate, both in my private and professional life. From my perch as an observer, l've lost faith in our ability to converse across ideological divides, so l've mostly excused myself, much to the detriment of my voice and agency. I've silenced myself. I have the opportunity, now, to face this discursive danger of non-participation, so I ask myself: How can I, in the public sphere of discourse outside of academia, participate in the interest of my ideals and my hope for future civil reconciliation and ecosystem restoration? I want to seize the opportunity granted by my rhetorical mid-life crisis and fight against the dual-crises of democratic decline and environmental destruction.

This opportunity is worth fighting for, so how can I fight for democracy's institutions and Mother Earth as a writer and a teacher of writing? Our exigencies are too immediate and too important to let languish because of a degraded rhetoric that garners the most outrage has infected our discourse, like a virus of incivility and disrespect, a pathology of partisanship that pervades every issue, even the issue of our planet's future viability to sustain life. To seize the opportunity to help in whatever meager way I can, I must improve my literary practice. I cannot be content with my content. I cannot stagnate pedagogically. I am in need of increased action and intensity. Am I stumbling? Have I lost my bearings? What is progress, for me, as a writer, as a teacher? How can I enhance my approach, my attack, both theoretically and practically? What resources can I draw upon, rely upon to fulfill my rhetorical potential and follow-through with cutting-edge compositional practices? I'm seeking stronger impact. How might my kendo experiences and readings in samurai ethics illuminate a path through my disappointing passivity?

On a positive note, I'm succeeding in my teaching and writing practice on a number of levels. First and foremost, I haven't given up. I remain a student and teacher. I've redeemed 
my academic folly of youth and built a career in education. I'm a decade into teaching writing, and I'm completing a master's thesis. I take pride in being a teacher and student of writing. I've made meaningful connections and earned positive feedback. I have worked hard in the interest of writing; I've attained a skill-set and consider myself competent (I earned tenure, after all), yet I'm so far from the level I hope to attain. I'll continue to strive.

I am feeling utterly exhausted, though, as an educator, student, writer, American citizen, and human being right now, like a beginner during the waning moments of a kendo practice. I'm heaving for breath, exhausted, knowing that I gave my best for the good of the practice despite my limitations. I'm furtively glancing at the clock, knowing l'll soon hear the final "Yamae!" to end practice for the day. I'm so hot and tired that I'm feeling chills and getting goosebumps. I'm light-headed and seeing spots. I like this feeling, though, this utter exhaustion. I know that I am improving because I have pushed myself to a limit. But the end of one day's practice is the beginning of the next, and I know I will show up.

I want to compose and guide young citizen writers with greater honor, duty, and purpose. I do not want to be listless, despondent, hopeless -- a teacher who doesn't connect, cannot inspire. That's what I'm afraid of: failing to connect, failing to strike my students and my audience with ideas and inquiries that move. I want to strike my students with ideas that get them interested in seeking more and digging deeper. I want to strike up conversations, debates, arguments. I want to strike with the urgency necessary at this specific moment, as we walk on the edge of a beautiful, deadly blade: the present moment.

Our shared exigencies feel existential. We have this accelerating crisis of confidence in vital democratic institutions, namely government, the press, and education. We also suffer from passively-destructive apathy and misinformation with regard to the climate crisis and ecosystem destruction. We're just consuming comfortably and being entertained, but we're failing to reckon or pay the costs. It's like we're taking out payday loans on our future. Our institutional and environmental crises are communal, yet l'm also facing a personal crisis of confidence in my 
resolve to best live and promote the ideals that I hold dear as a teacher, citizen, and human being. I want to live my ideals more richly through inquiry and action and promote these ideals and actions more stridently through discourse and publication.

Americans today suffer a crisis of good faith deliberative discourse. We're no longer civil in our debates, if we even get to an actual debate on a specific policy issue. Remember that first presidential debate of the 2020 election? (No? That's okay; I tried to repress it, too.) This is extremely dangerous in an age when change is accelerating, and we must be nimble in our action plans. We now have the opportunity to fight for our future by redeeming the state of our discourse and intellectual rigor, and that must happen in the public school system. I have a duty to prepare my students to be responsible, respectful citizens in our American democracy and curious, compassionate human beings who debate and plan with optimism and hope tempered with skeptical critical-thinking. In my own composition and my classroom, I must actively battle the dangerous anti-intellectualism and disregard for expertise that pervades American culture. I need courage to act with increased tenacity. How can I use my kendo in my teaching of writing to promote the ideals and processes of our democracy? How can I use my kendo to imbue my own composition with power to help me live how I want to live and promote sustainability in my actions and in our systems?

The urgent reality is that we are at a breaking point in humanity's tension between our creative and destructive drives while l'm oscillating between poles of urgent communal dread and despondent solipsism. Humanity has never held so much power in its hands. Our communication technology, body of knowledge, and economic efficiency are awe-inspiring testaments to human ingenuity, but we are hemorrhaging carbon dioxide and plastic. Can we discover and pursue solutions? Can we rehabilitate our consumer and corporate behavior? Can we reimagine and reinvent our systems? Can we revive cooperation? The climate catastrophe feels imminent, yet consumer culture's quality of life and standard of living induce a 
sedate complacency in the economically secure and poverty restricts the agency and power of the poor, those who suffer the disproportionate effects of climate change and pollution.

I am running out of time to contribute my labor to the causes of democracy and environmentalism. I am forty years old; the clock is ticking. We are all running out of time. I want to contribute to the restoration of belief and trust in our institutions, our discourse, and our future. I want to better represent myself and my values in both word and deed, as a writer, teacher, citizen and human being. I want to more effectively challenge my students to inquire deeply into our institutions and issues in a meaningful way that can lead to solutions and actions. I want to attack these crises full-force with all the furious subtlety of a kendo strike.

\section{Theoretical Framework: Integrating My Practices}

A scholarly framework exists supporting the methodological approach to my project: "Interdisciplinary research literally means research between disciplines, referring to the interaction of disciplines with each other... Such interaction may range from mere communication and comparison of ideas, through the exchange of data, methods, and procedures, to the mutual integration of organizing concepts, theories, methodologies, and epistemological principles" (Menken 31). As the Japanese cultural elements of kendo practice arguably fall under the purview of Cultural Studies, this multidisciplinary theory is apt.

However, kendo itself is not a field of study in academia, so my project also has the tenor of transdisciplinary research that "involves actors from fields outside the university, thereby allowing for the integration of academic and non-academic or experiential knowledge" (Menken 32). Menken, et al goes on to further define transdisciplinary research, which is worth noting, as it essentially describes exactly what I intended to achieve with my thesis: "Transdisciplinary research occurs when researchers collaborate with stakeholders from outside the academic world. Knowledge from outside the academic world, as well as stakeholder values, is integrated with academic knowledge. Together, these insights determine what problem is studied and how 
this is done, and which interventions are selected to address the problem" (Menken 32). Mine is perhaps a novel take on this relationship between academic researcher and non-academic stakeholder because I am serving in both roles: I'm excited to wear both masks simultaneously.

My project is an interdisciplinary and transdisciplinary endeavor, putting the academic field of Rhetoric and Composition in conversation with the martial art of kendo, a living symbol of Japanese culture and history, with the purpose of understanding how best to move an audience and participate in cohesive communities. I aim to integrate knowledge from each discipline to generate approaches that will enhance my practice in each field: "integration is a process by which ideas, data and information, methods, tools, concepts, and/or theories from two or more disciplines are synthesized, connected, or blended" (Repko 3,4). This integration will strive for mutual illumination of teaching and composing and the art of Japanese fencing.

Much of the kendo philosophy is deeply rooted in the classical Japanese warrior ethic: Bushido. Therefore, my inquiry will delve into samurai philosophy, morality, and ethics, along with contemporary aspects of kendo. I will integrate cross-cultural and multilingual elements as I explore questions and problems that have been revealed in my experiences in public discursive spaces, the ELA classroom, and the dojo. By examining teaching and composing through a kendo lens, I aim to improve my teaching and composing practices. Similarly, I expect my research and experience with rhetoric and composition and teaching to inform and improve my kendo practice, too.

My methodology begins with experience, having simultaneously studied and practiced as an English Language Arts teacher, a student and writer in higher education, and kendoka for the past decade. These are each vital elements of my identity, and my experiences will inform much of my inquiry, as some of my insights and guiding principles have been gleaned from my ELA teaching mentors, my colleagues and professors, and kendo sensei.

I will also ground my inquiry in philosophical, pedagogical, and informative texts associated with composition, teaching, and kendo practice. Ultimately, my mission is to elevate 
the quality of my composition, my teaching, and my kendo through this trans/interdisciplinary mutual illumination.

\section{My Vocation and Location}

I'm entering my ninth year of teaching secondary English Language Arts (my tenth, including student-teaching and a semester of subbing). I've been a writing enthusiast for the entirety of my education, which was interrupted in my early-20s yet resumed in my late 20 s, when I endeavored to re-enroll and complete my bachelor's in English at Dartmouth College. Since my decision to recommit myself to literacy education as my path, I've been engaged in academic writing and scholarship. After belatedly taking my bachelor's, I enrolled at Illinois State University to earn my teacher certification, which required two additional years of undergraduate coursework and student-teaching. I soon enrolled in my first course as a graduate student at ISU in the post-bac certificate in the teaching of writing program, which served as a gateway to what is now culminating with an MS in English Studies with a focus in Rhetoric and Composition. I've been writing in the academy for a solid twelve years straight, which feels like an accomplishment. I've written to learn so much over the years, and I am grateful for what has been revealed about my identity and my purpose in life through the writing associated with my education.

My education in composition studies has opened pathways for progress in my teaching pedagogy and offered a supportive writing community to which I could contribute. A highlight of my graduate studies, I was introduced to and corresponded with the sagacious Dr. Peter Elbow, author of Writing Without Teachers, which greatly informed my practice as both compositionist and teacher, particularly in my understanding of writing to learn and composition as an act of discovery: "Meaning is not what you start with but what you end up with" (15). My teaching of writing has evolved to prioritize revision based on qualitative written feedback, reader-based peer-response, writing workshops, portfolio assessment, and meta-cognitive self-evaluation for 
my students. My assessment strategies are influenced by Maja Wilson's Rethinking Rubrics in Writing Assessment, which revealed assessment strategies that go beyond reductionist categories and tabulating points. I have been influenced greatly by Asao Inoue's Labor-Based Grading Contracts: Building Equity and Inclusion in the Compassionate Writing Classroom (2019), and just last year I began offering a "grading promise" to my students that emphasizes and rewards good faith participation and revision. I have confidence in these elements of my work as a writing teacher.

I've only published in a scholarly journal once, though, but I am proud of the artifact. My scholarly research article published in a special edition of the Illinois English Bulletin is entitled "A Spectrum of Perspectives: Believing in Democracy by Writing to Learn." I regret that the exigency and urgency of that article, composed in the wake of the 2016 election cycle, seems quaint compared to where we are now with the state of our democracy and public discourse.

I am also in my tenth year of kendo practice. I have been a dedicated kendoka from the outset. I've attacked every practice possible, ideally twice a week. I practiced the day my third son Ernest was born, after he was born. I've been humbled by kendo. I've been girded. My access to kendo has been limited during the pandemic, obviously, but we are back in action. I missed actively practicing kendo in my life in so many ways. The lack of outlet for my energy and aggression wore on me, let alone the sudden absence of people I had grown accustomed to spending so much time with, especially Nobu-san.

My sensei, the leader and teacher of the Bloomington-Normal Kendo Club (BNKC), is Dr. Nobu Tanaka, who moved from Japan to the States when he was 35, in the mid-70s. Nobu-san is a mountain, a totem, a mentor, and a friend. I have spent hour after hour with Nobu-san both at the dojo (now at the gym of the Salvation Army) and at kampai, which is fellowship time at the pub after kendo practice; Nobu-san always called it "second practice." Besides my wife, Charity, and my three sons (Elvis, Walter, and Ernest), I have spent more time with Nobu-san than with any other person on earth, by a long shot, over the past decade. Nobu-san loves kendo, and 
has been with the BNKC from nearly the beginning when the club was founded by Sakai-sensei, an executive from Japan at the Mitsubishi auto plant in Normal that opened in the mid-90s;

Mitsubishi has now departed but the kendo club remains. Nobu-san is the oldest active practitioner of kendo in the midwest, so it's an honor and a privilege to be with him. His commitment to lifelong achievement and to testing himself against himself into his 9th decade is inspiring. Much of my dedication to kendo has been inspired by Nobu-san.

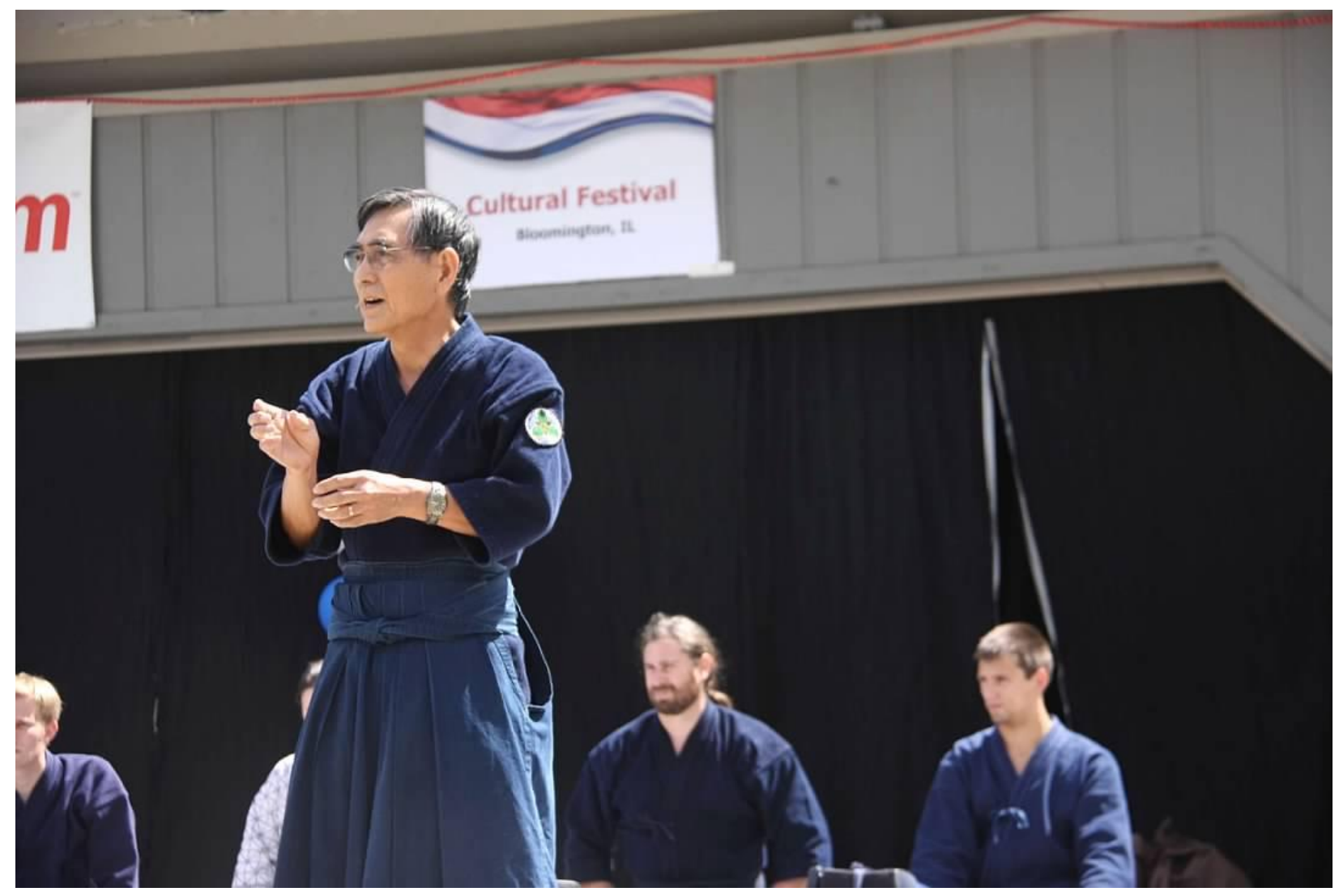

Figure 2: Bloomington-Normal cultural festival, Miller Park (2011)

The goal is to practice kendo twice a week, every week. Week in, week out. l've pursued kendo seriously, and l've been forged. Not that I'm finished; I'm just starting to cut. I hold the modest rank of sho-dan, akin to first-degree blackbelt. I humbly approach this thesis project as a steadfast student with "beginner's mind." My understanding is limited, but I will strive to respect and represent kendoka to the best of my ability. Here in central Illinois, we 
enjoy a modest kendo community, but I understand that our club is part of a great whole, including the Midwest Kendo Federation and the All-United States Kendo Federation.

My shugyo (修業) is deeply rooted in literacy, not just in the sense of my profession, but in my kendo practice and study. Shugyo is a pursuit of knowledge, a quest to progress. Shugyo takes myriad forms and innumerable paths. My shugyo is deeply involved in being a teacher, student, writer, and kendoka. I've read a decent amount about kendo and samurai ethics as part of my shugyo. My reading of contemporary kendo literature is rather significant, yet I am clearly limited in my knowledge and access to kendo literature because I cannot read Japanese. That's what I most appreciate about reading kendo blogs like Kenshi24/7 and Kendo-info.net: these high-ranking sensei translate and discuss essays from the history of kendo.

I've dabbled in the classic texts: The Unfettered Mind (Takuan); The Life-Giving Sword (Yagyu); Hagakure: The Book of the Samurai (Yamamoto); The Book of Five Rings (Musashi), and Bushido: The Soul of Japan (Nitobe). In terms of creative writing, the Musashi manga Vagabond and the novels Musashi (Yoshikawa) and Shogun (Clavell) are my pillars.

I have also written about kendo for shinsa (promotion tests), which require approved essays prior to physical examination. I feel a strong link between my literacy practices and my kendo practice, and I sense the potential for even greater connection. This need for integration lies at the heart of the purpose of practicing kendo, as articulated by All Japan Kendo Federation in 1975:

The purpose of practicing Kendo is:

To mold the mind and body,

To cultivate a vigorous spirit,

And through correct and rigid training,

To strive for improvement in the art of Kendo,

To hold in esteem human courtesy and honor,

To associate with others with sincerity, 
And to forever pursue the cultivation of oneself.

This will make one be able:

To love his/her country and society,

To contribute to the development of culture

And to promote peace and prosperity among all peoples.

\section{Ki-ken-tai-ichi}

Recently, Nobu-san pulled me aside during waza practice. "Something's off with your ki-ken-tai-ichi," he said, with his head tilted and a somewhat perplexed glimmer in his eye. "I'm not exactly sure what it is," he continued, making striking motions with a phantom shinai, still thinking. "Remember, ki-ken-tai... ICHI!" He stomped his foot in fumikomi as his hands flashed forward, and he let out a sharp sound, all simultaneously. "Ki-ken-tai... ICHI! ICHI! All at the same time. You must strike simultaneously -- with spirit, sword, body -- all at the same time. Someone with your experience and skill level should be sharper, so sharpen up. Remember ki-ken-tai-ichi."

"Hail" I shouted seriously with furrowed brow under my mengane, rather humbled. Yet the correction and reminder of my ki-ken-tai, especially the harmonious ideal of ichi, was a catalyst to meaningful intention for the rest of that practice and my ensuing practices.

Every kendo encounter is a rhetorical situation, and there are various modalities of kendo. One is tournament kendo (shiai), which is generally the most intense. During matches, three referees (shinpon) actively triangulate the competitors and raise red or white flags to award a point (ippon) when two agree that a strike displays skillful unity of spirit, sword, and body (ki-ken-tai-ichi). The purpose is to score a point by symbolically cutting down one's opponent, both strong and beautiful. If any element is off, the strike will not resonate, the sword will not cut, and the judges will not be moved. 
I'm considering and applying this ideal of ki-ken-tai-ichi to composition and teaching to seek opportunity where I have been mired in passivity. I will also investigate enhancing my ki-ken-tai and kendo practice, in general, with concepts and experience from writing and teaching that correspond with spirit, sword, and body: ethos, pen, and action. As I consider each element separately, I will strive to seek the connections, intersections, and opportunities to synchronize this trinity. A strike is only valid when all three are in unison. I hope that I do not neglect the importance of ichi with my rather reductionist framework for this inquiry that investigates the elements independently. I can never lose sight that ki-ken-tai only resonates when in harmony. The ideal is that I move towards enthusiastically participating by publishing multimodal content documenting activity that reveals who I am and what I value. By committing myself to publishing my composition (even if it's just hitting "post"), I'll also be spurring myself to increased activity, more frequent action, and the possibility of bonafide activism, of which there is currently a dearth in my life. I have many instructive examples to choose from for how I hope to represent myself to the public online spaces, so I need to get into it. There's an extensive digitized ecosystem of democratized discourse going on out there waiting for me to engage. What might I derive from kendo to instruct how I intend to compose and communicate when I do finally compose for a public audience in an online space? I want to make an impact, yet I want to transcend the bitter partisanship of our times. I don't want to be petty, and I fear being inconsequential. The only way to guarantee my own irrelevance, though, is by not participating. Delving into the literature, in search of the crossroads of ki-ken-tai-ichi and teaching composition, I encountered one particular book that spoke to this moment and my inquiry: Teaching for a Living Democracy: Project-based Learning in the English and History Classroom (Block, 2020). Block offers valuable examples of his teaching practices that can alleviate the anxiety l've been feeling about my passivity, my avoidance of issues, and my guilt about not doing enough as a teacher in this time of crisis. Block's pedagogy is aimed directly at the target that I want to start attacking: "In this vision of education, classrooms are communities grappling 
with issues and conflicts while creating products and ideas" (Block 3). This vision is exactly what I will work towards as I challenge myself to progress in my practice. I've been humbled by Block's example, but l've also been inspired. As his recent iteration of project-based learning is so valuable to my perception of ki-ken-tai-ichi in the classroom, I am grateful to have found it seemingly by chance, as I was searching for another book on the 6th-floor shelves in Milner Library. Just like I came across the BNKC seemingly by chance in what now feels like divine providence, my encounter with this book was hinged on a glance, yet it feels like it was meant to be. 


\section{CHAPTER II: KI AND ETHOS}

$K i$ 気 (noun): spirit; mind, heart; nature; disposition; motivation; intention; mood; feelings; ambience; atmosphere

Ethos (noun): 1) the fundamental character or spirit of a culture; the underlying sentiment that informs the beliefs, customs, or practices of a group or society; dominant assumptions of a people or period;

2) the character or disposition of a community, group, person, etc.

3) the moral element in dramatic literature that determines a character's action rather than his or her thought or emotion.

\section{Introduction: Summoning the Fighting Spirit}

$K i$ is the foundation of ki-ken-tai. The sword and the body are nothing without a staunch spirit. The moment I rise from sankyo (a ritual acknowledgment of mutual respect that involves squatting in unison with one's foe), looking my opponent in the eye, is the time to summon and proclaim my power and intention with strong kiai. This deep sound is a vocalized manifestation of spirit, brought forth from guttural depths. Kiai declares being and presence, its reverberations distilled from the sweat of keiko. Kiai is sudden, forceful, free. "I'm here to fight! I will prevail or I shall perish!" My kiai is a declaration of who I am in the moment of conflict. In the dojo, kiai is my voice. I attack with a full spirit of commitment to my one strike, with uchikiru. Kiai is drawn from the inner-wellspring of ki. In shiai, right after sankyo and before the first strike, shinpon will already have discerned between the two combatants, purely from the quality of kiai. I strengthen my ki with confidence built one practice at a time. In kendo, one wins by killing the sword, killing the technique, or killing the spirit of one's adversary. One's ki must always match that of one's adversary to even have a chance in the clash of technique and swords. 
How can I strengthen the ki of my composition? By building my ethos. Ethos is the foundation of rhetoric and composition. Just like I infuse my kiai with my hard-earned spirit, so too I strive to infuse my composition with hard-earned ethos. Composition is full of spirit, too, a mode of self-expression. Composition is a representation, an artifact of who we are and what we value. It is the vessel that carries our ethos to its destination: an audience. Ethos is established with every moment, with every word. We seek knowledge and experience to bolster ethos with credibility and trustworthiness. Rhetoric is ineffective without strong ethos.

But how do I strengthen my ethos with regard to democratic institutions and the environmental movement? What are the practices through which I can strive to instill and develop my ethos? In what specific ways is my ethos as a writer and a teacher of writing in need of strengthening and improvement? One thing is certain, being passive is not the way.

\section{The Kendo Fighting Spirit}

Kendo is samurai sword-fighting. It's a fight, plain and simple: "You must train for kendo with the understanding that if you cannot cut your opponent, he is going to cut you" (Salmon 2). One can never lose touch with that essence: the fight. Kendo is highly aggressive, as we attempt to symbolically cut down -- to kill! -- our opponent. Being cut down, even symbolically with a bamboo shinai, is humbling and often stings on a physical and emotional level. However, kendoka cannot take it personally when attacked, when struck, or when defeated. Ideally, one even feels satisfaction for an opponent who scores ippon with effective ki-ken-tai-ichi. We fight with mutually beneficial respect that is embedded in codified routines, outward signs of etiquette.

Constructive civil discourse requires a spirit of respectful clashes, of good-natured sparring, of a willingness to fight, yes, but to "die" honorably. This competitive spirit has roots in the classical Greek's agon, its term for struggle, conflict, or contest. Does that mean that a rhetorician, a writer, a thinker, a voter in a democracy must be willing to accept defeat? To let 
one's misconceptions, misperceptions, miscalculations, or misgivings die when rhetorically defeated? Yes. Absolutely. One of my favorite quotes ever is from Emerson's Self-Reliance: "A foolish constancy is the hobgoblin of small minds." To lose but never concede one's loss is foolish bad-faith, deluded and delusional. Anyone who seeks wisdom, growth, solutions, or righteousness must be willing to be swayed, to be moved, to begin in one place yet end up in another, to consider testimony, to question belief. That same good-faith thinker, writer, teacher will also represent one's position as firmly as possible up until the point of its defeat. But admit defeat we must.

So what does that intellectual "defeat" actually look like? Progress and growth. When I change my position on an issue, it's because l've been open-minded and willing to admit to myself intellectually that I was wrong or not fully informed. Usually, however, kendo is not about winning or losing; it's about personal progress, so in my teaching I plan to focus not on the idea of ideas winning or losing in relation to the issues but on the value of the open-minded inquiry itself. There's typically not much keeping score in the dojo; it's just about the spirit of action, and each individual knows the score with regard to their personal progress. Kendo is not about fighting others; it's about forging oneself. This needs to be articulated clearly to my students as we attack more kairotic, inflamed topics.

In order to practice kendo, one needs cooperation. Even though we're fighting, we must remain respectful and polite. An attack in kendo should never be personal although I have seen and experienced jikeiko (sparring) degrade into an emotional fight, both with beginners and with sensei. Therefore, we have rigid, codified routines in the dojo that inculcate mutual politeness and respect among those who are there to engage in an aggressive facsimile of killing each other like samurai warriors.

A mutual respect and politeness, rooted in etiquette, is vital for meaningful intellectual sparring, too, yet we are sorely lacking in this regard as a society. We're just shouting over each other and preaching to the choir. In our fractured media and ideological landscape, there 
is very little healthy, civil debate of the issues plaguing our institutions and our planet. Even the US Senate, which is purportedly the world's greatest deliberative body populated by our most august citizens, fails horribly in this regard. There is currently very little good faith debate in the US senate -- or nearly anywhere else in our adult society. The party-line vote on the American Rescue Plan, after the counter-offer was, like, 1/3 of the original proposal? Filibustering the For the People Act that promotes greater participation in our elections? Bad faith. If adults who are considered the best qualified among us to represent the will of the people in Congress cannot engage in respectful, civil discussion and open-minded debate, how can we expect that standard of civility and debate of the young people in our classrooms or of compositionists who are aware of the ideological fervor of their intended audiences? Are we too far gone to engage in discourse with a fighting spirit that prioritizes respect, open-mindedness, and willingness to suffer defeat with dignity, to change one's position based on evidence or logic? Much of what I've observed as an American since the beginning of Nov. 2020 has me doubting our ability to collectively recover our civility and productive discourse between ideological adversaries. But I need to stop complaining and start participating, but not in accordance with the mean-spiritedness of our moment. I am really down about where we are politically and culturally, though.

Republicans apparently want to take the Big Lie with them to their graves. The right-wing media machine continues to whip Americans into a frenzy with blatant lies day after day about the legitimacy of our democracy and the trust they should have for institutions? Yesterday it was a lie about the government buying and handing out Vice-President Harris's children's book to migrants at the border, and today it was Biden's climate plan restricting red meat consumption to one burger a month. Pure nonsense, but this is where we are. It's sickening how degraded our civil discourse has fallen and how much we have fallen prey to lies, misinformation, and abject fear. We ought to be ashamed of ourselves. I am. If there's any hope of re-capturing civility and a shared reality in our society, it must start in our educational 
system, in our classrooms, in my classroom. But l'm failing. I cannot continue to look the other way, as if we're not fully in crisis mode as a society. I don't want to be alarmist, but I do want to be real with my students.

My fighting spirit has never been at a lower ebb than it is right now in the first half of 2021 , both as a writer who hopes to engage the public in good faith and an educator who hopes to inspire curious, well-informed, open-minded members of our democracy. On today's pressing issues, there's just no seeing eye-to-eye, no agreeing on a shared reality, no finding common ground upon which to engage rhetorically with the opposition. The implications of rhetoric have never been higher stakes than they are right now. Climate change is an existential threat, along with habitat destruction, ecosystem disruption, deforestation, deregulation, bleaching corals, ocean acidification, plastic pollution, greenhouse gas emissions, overpopulation, chemical contamination, nitrate runoff, and factory farming cesspools.

We have problems, serious problems with far-reaching implications. The magnitude of our power to create and destroy has exponentially exploded in equal measure. We have created quite a remarkable human civilization, but what is the cost of our standard of living and quality of life, which are simply astounding when juxtaposed with all but a sliver of human experience before ours? The question is: Can we use our rhetoric and a fighting spirit to mitigate these problems, or will our opportunity be wasted in the spirit of bad-faith? I want to fight for a sustainable, civil future. Is it possible? If so, we need a way back to a shared reality, a respect for honest inquiry and spirited debate. Project-based learning will be my way of contributing to a shift back to cooperation and communication: "Instead of a self-contained space, class becomes a place for communication with outside experts and for exploring connections between students' lived realities and course content. Class time is devoted to collaboration, student design and decision-making, and critical feedback for the work of peers, not to competition" (Block 9). This captures the essence of the kendo fighting spirit: it's about cooperation, not competition. 
My fighting spirit as a compositionist is in purgatory as a writer who is soon to be without an audience or an outlet for my voice. I've written much and worked with many wonderful people during graduate school. I've been afforded ample opportunity to listen, speak, read, and write. I've enjoyed community and support. I've conversed with kindred spirits. I highly value my time, energy, and accomplishment at the university. However, although ISU is a public institution, it's not the general public, so my contribution to this setting has been shared with a sympathetic audience. I need to branch out. I might not ever be able to civilly engage in good-faith with some of these anti-vax, anti-choice, White Christian nationalist, gun-worshipping, Q-researching, vote-suppressing Americans, but I certainly never will if I don't try. I want to contribute to inviting and persuading them back to a shared reality from which we can actually make progress towards a better future. I don't even know if this possibility exists anymore, in this age of media polarization in our post-fact world. Where do the two ideological echo chambers overlap? Where do Americans of all stripes go to debate? Is it at college? Hopefully. But not everybody goes to college. Where can I engage a spirit of serious, good faith discourse for the general public? Where is the spirit of cooperation, collaboration, compromise, and conciliation? Why can't we fight over the best way to solve our problems instead of fighting over whether the problems exist? They exist! Now let's respect one another as Americans and seek out the best way forward, together.

I obviously lament that I too often pass over serious debate of kairotic, arguably controversial topics in my classroom, but l've experienced that even teens have started to harden along ideological lines. I have been sapped of my fighting spirit as a high school English teacher after dealing with this reality in my interactions with ideologically combative students. I'm not proud of this, but I am failing to bring my kendo fighting spirit into my classroom. My teaching is not in harmony with the purpose of practicing kendo, and the ideal of my kendo practice permeating other aspects of my life. Much of my passivity is rooted in the caustic social 
and political landscape of our deeply divided country. I've been rather traumatized by the past half-decade, especially the past 18 months, and l've turned inward. This is not the way.

The fact is that, although I will offer my students platitudes about tolerance and the perils of racism, sexism, and bigotry, I do not offer meaningful inquiry, discussion, or debate about systemic racism in our institutions, white privilege, toxic masculinity, abortion, police brutality, gun violence, climate denialism, capital punishment, anti-vaxxing, "religious freedom," or LGBTQ rights through extensive use of contemporary texts. I confess that I'm simply not willing to listen to my students parrot right-wing political ideology, which is so often anathema to me. I don't want to think less of the community in which I teach, and I don't want the unpleasantness of the conflict. The fact is that I teach to a nearly all-white clientele in a rural community in a county that went for the incumbent in the 2020 presidential election by a staggering 58 points (79\% of the vote). I shudder. On Jan. 7 th, 2020 , my regretful reticence to engage my students in a kairotic, meaningful issue that would require the fighting spirit was made crystal clear, laid bare in the starkest of terms -- and I feel rather ashamed, in retrospect.

The only other English teacher at my high school is a 1st-year teacher. On that particular morning, the morning after the violent storming of the U.S. Capitol by crazed insurrectionists drunk on the Big Lie, this young teacher came to me for insight and guidance: What was I going to do or say to my students with regard to the insurrection at the Capitol, perpetrated at the behest of a sitting President of the United States? How was I going to engage my students with regard to this historical moment, this attack on our democracy carried out by our fellow Americans? What opportunity would I give my students to learn about or discuss what happened?

My response to her can be summed up in one word: Nothing. I wasn't going to do anything. We were going to read "The Scarlet Ibis," just as I had planned before the desecration of our most sacred symbol and seat of government. I tried to obscure my cowardice with excuses like, "I'm their English teacher, not their political-science or government teacher." 
Looking back, I'm genuinely ashamed of my fear. But I was afraid of the discussion degrading into students' decrying a stolen election, ridiculing President-elect Biden and Vice-president Harris, condemning "democrat cities" as corrupt thieves, or praising the criminal insurrectionists as true American patriots who were fighting on behalf of God to keep our country from falling into the grip of satanists. So I just ignored the elephant in the room (pun intended, sorry), and conducted my class as if it were any other day. Sad and shameful passivity, I know. I did not trust myself to remain calm, honestly.

Not only did I fail my students the morning after that shameful day, but I failed to be a courageous mentor for my young colleague, as well. I was not confident in my ability or my students' ability to engage the issue with mutual respect. I had not fostered the discipline necessary in myself necessary to be confident in rising to the moment in a constructive manner. So I didn't even try. I failed. What can I do to fix this lack of confidence in the spirit of my teaching, of my classroom? It has to start with building an outward culture of respect, starting with me; if I, the teacher and the adult, cannot talk about these issues, how can I expect that of my students? Too often, our public rhetoric feeds a culture of demonization, so I need to model and live an ethos of respect for one another and a respect for knowledge by not being passive in the face of conflict or argument.

\section{Rei-ho}

Although kendo is quite literally a fight, the manner in which we fight is of the utmost importance. In the dojo, we have a rigid code of etiquette that is embedded in routines that involve both action and words to foster and communicate mutual respect and commitment to one another's personal growth and improvement. In Japanese culture, this code of etiquette is rei-ho, and it is vital. The repetitive routines and expectations of rei-ho keep respect at the forefront of kendo practice, even when we're rather viciously attacking each other with blows to the head and wrists. Rarely does the fighting spirit of kendo boil over into anger or malice. Aggression is absolutely essential in kendo, so we must temper our aggression with mutual 
respect and manners. If our aggressiveness is not tempered with respect inculcated with etiquette, the kendo will degrade. Perhaps that's why our discourse in America is so degraded: the dearth of routine, outward displays of respect.

How can I establish routines of respect in my classroom that likewise foster the spirit of collaboration and goodwill that are necessary to engage students in our imperative yet sensitive issues of trust in democratic institutions and environmentalism? I must mindfully foster a fighting spirit in my classroom that involves mutual respect and goodwill with my own routines and daily outward displays of rei-ho. I need to build confidence in myself by designing projects in the spirit of respecting my students' ability and intellect, that show my students that I respect them by inviting them into these massively important issues to explore and learn. I'm so excited to dive into project-based learning because it truly puts students at the center: "Rather than listening to me tell then all they should have learned, they had to step into the role of investigators who then had to process and contextualize their findings" (Block 19). This is how to show more respect for my students, beyond outward gestures of etiquette: by offering them project opportunities situated at the intersection of their identities as Americans and the urgent issues in need of our energy. Implementing project-based learning will absolutely make a positive impact in my classroom culture, but how else can I cultivate a spirit of cooperation and trust?

Rei-ho begins the moment one approaches the dojo. First, we remove our shoes before stepping through the door. This act reflects respect for the physical space of the dojo itself. Obviously, I cannot ask my students to remove their shoes before entering my classroom, so what can I do to embed respect for the classroom as a sanctified space in our daily routines? Without inherent respect for the classroom itself, both for what it symbolizes and for what it literally offers on a daily basis, we cannot get to a place of voluntary, engaged learning. Kendoka enter the dojo actively choosing to be there, choosing to practice. However, high school students often see themselves as a captive audience, not willing practitioners of 
education but victims who are having school foisted upon them. This is a problem. Again, I can sanctify my classroom space by respecting those who populate it: my students. I cannot fail them with passivity.

Rei-ho continues in the dojo when we line up for seiza. We organize ourselves from left to right in a specific order. Some dojos line up by official rank while others line up by seniority. My dojo uses a blend: we line up mostly by rank, but we have more seasoned members take a spot of honor farther to the left, regardless of rank. We bow to our kakejiku (hanging scroll) and to the group in general, inviting each other to practice respectfully. At the far left of the line, though, for every practice and in every dojo, is the sensei. Each dojo takes on the character of its sensei, which proves true in education, too.

\section{The Teacher Ethos: Tranquility}

Every classroom reflects the ethos of its teacher, just as each dojo practices in the fighting spirit of its sensei. How can I, the sensei of my classroom, lead the way to a fighting spirit of civil discourse -- of aggressive inquiry and debate -- that is invigorating, challenging, and empowering, despite the sharp stings that follow when one's argument or position is met with opposition?

An ideal is for sensei to always remain calm, even when attacked unexpectedly, sloppily, or hyper-aggressively. This is what I fear in my teaching and why I hesitate to engage with students on fight-worthy topics, like election-integrity and offshore drilling: losing my composure. This is not in accordance with the ideals of the samurai code: "The spiritual aspect of valour is evidenced by composure -- calm presence of mind. Tranquility is courage in repose" (Nitobe 52). Now that l've realized my passivity is very much rooted in not trusting in my own composure, I have a focus and a path to overcoming my personal crisis. Losing composure in the face of an affront to one's beliefs is a reality in the dojo, as well as in the classroom. 
A member of the BNKC, while visiting another dojo, provoked its sensei, and the sensei's reaction became a topic of conversation at kampai for weeks afterward. Flo-san had been tearing up ippon-shobu (one-point sparring matches) until, after defeating seven straight opponents, the sensei stepped in to assert himself. In a way, he was fighting for the honor of his dojo against this marauding visitor. As soon as they rose from sankyo, Flo-san hit sensei with the most aggressive, arguably disrespectful attack in the kendo arsenal: the long-range, one-handed tsuki, straight to the throat. It's a legal strike, yet highly questionable, given the rhetorical situation of the encounter. Sensei, however, lost his composure and furiously, emotionally attacked Flo-san, unleashing a flurry of attacks, including many tsuki in what was clearly an angry reaction to having been attacked in a manner he considered disrespectful and overly aggressive, which is ironic because kendo idealizes aggression. Flo-san, however, did not back down, and the ensuing fight resembled more of a kendo death-match than a good-natured sparring session.

Sensei was out for blood. It got objectively ugly, as the two were evenly matched physically, and although Flo-san is not sensei, he had many years of practice at various dojo, including in Japan. When the dust had settled, sensei communicated directly to Flo-san that he should not even bother testing for his next ranking anytime soon, as Flo's kendo was "not a good example for the children." Sensei made clear that he would not permit him to pass his upcoming shinsa (promotion test). Shinsa examination is rather closed-book. A panel of sensei judge kata (choreographed routines with wooden swords) and make necessary cuts, followed by jikeiko (sparring) for about a minute, after which you either pass or fail. No formal notes. No official feedback. No open-book scoring system. It's a testing model in which a personal grudge could preclude promotion. Seems harsh, which it was because Flo-san never tested. He hasn't been around the dojo in quite some time, not much at all after the incident. I'm afraid the negative experience soured him. This makes me nervous because right before the pandemic hit, in the very first strike of my first match of taikai, I knocked down my opponent, 
which is not uncommon in a shiai match. Yet this was rather different, and I got a reaction from a sensei that is quite different from the anger Flo experienced but still stung: passive condemnation. I've worked on not letting it deter me, but l've thought about the experience quite a bit, in terms of my lack of awareness and the sensei's approach to criticism.

I should have done more research on my opponent, because when I went down into sankyo, and looked into my opponent's eyes, I had the question flash through my mind, "Is that an old lady?" An instant later, I instinctively struck men like l've practiced 10,000 times... and she went down. She wasn't injured, but she laid still and didn't get up for a full minute and quit the match. I bowed at her feet, apologizing profusely, but the damage was done. Even after I won two following matches before losing in the semi-finals of the tournament, a sensei I had never met says to me, in passing without breaking stride, "What you're doing, that's not kendo." I was rather taken aback, and it cut deep, as he just continued walking without a second glance.

I didn't mean to knock her down! l've practiced twice a week for years on end with an elderly man, and I've never once knocked him down once. Then the sensei who didn't like my kendo admonished old Nobu-san about it the next day at shinsa, like, "Nobu must do better; you must teach better!" He admonished Nobu-san, himself a revered elder, because I knocked down the old lady. I wasn't present at shinsa to apologize or explain; Nobu-san hadn't been at shiai the day before, so he had no clue what this sensei was complaining to him about, and was rather confused. Obviously, I felt terrible and embarrassed about the whole thing. There's video of it, and this woman's feet were both off the ground at the moment of impact, so she just went spinning down. It may have been poor footwork on her part, but it was too much force on my part, inconsiderate of the nature of my opponent. I was oblivious to the rhetorical situation of my shiai match. I wish my fighting spirit had been tempered with more cooperation and consideration for that match. I've brooded over that casually cutting criticism, made in passing, and I've yet to be able to let it go, mostly. What you're doing, that's not kendo. It hurt. I had 
been practicing for eight years at that point. I just wish he hadn't confronted Nobu about it like it was his fault.

After Flo-san's vicious scrap, our dojo members' spirited debate at kampai questioned whether it was not Flo-san who didn't set a good example for the children, but rather sensei who had reacted poorly and demonstrated un-sensei-like behavior? Not that it is my place to criticize or judge, I believe the latter: that it ought to have been sensei's duty and responsibility to remain calm, to keep his composure, and to set the tone for respectful fighting (and even acknowledge when he had been taken by surprise and lost ippon-shobu, if that indeed was the case). As a teacher, I admit I fear an emotional reaction in myself with regard to debating kairotic, sensitive, ideologically-fraught contemporary issues with my students, issues like systemic racism in education or the Covid vaccine. But if students cannot engage these issues in a meaningful way at school, then where will it happen?

I have to do better. A healthy democracy must have functioning rhetorical processes to discern which path forward is best. I need to model and instill the spirit of good-faith inquiry in my students, so they can be responsible citizens of our democracy and compassionate, forward-thinking human beings. I hang my head as I lament that I'm not generating this spirit of inquiry in my classroom because I'm avoiding conflict, which is so very ironic for a guy whose primary hobby is aggressively sword-fighting. Why have I become so passive, so withdrawn?

I feel strongly about issues, and I have been drawn into the partisan vortex of demonizing the opposition, too. I know that on hot-button topics, many students will offer their parents' ideology, and that by arguing with their positions, I'll be fighting with their parents by proxy. That contributes to why my fighting spirit has waned to such a great extent in my classroom: I'm not interested in conflict with parents over political ideology. However, if I can inculcate a certain level of rei-ho and a good-faith fighting spirit that insulates my classroom against inflamed passions and injured pride (mine, very much so), I can approach my goal of engaging my students in a meaningful way on today's most pressing issues. I must control my 
emotions as expressed by my words and tone in order to model civil discourse in my classroom. I want to generate some kind of ritual for showing respect and good-faith before diving into inquiry of heated issues. Should I bow to my students with an "onegaishimasu," like I do over and over during the course of a kendo practice? Nobu-san explained this phrase as a respectful invitation that communicates goodwill. We say this phrase literally dozens of times every kendo practice, so should I say it to my students with a respectful bow to begin every class? Yes. I may garner some chuckles early on, but it only takes a moment, and it will be a daily reminder to my students that I respect them and will offer my energy for our mutual intellectual pursuits. In the same spirit, I will close each class with a bow and "arigato gozaimasu," which is essentially the "thank you" phrase that we also repeat dozens of times every practice. In kendo, we open and close literally every single exchange with these two phrases.

Beyond showing my students outward displays of etiquette, I must be clear with my students about my responsibility as their teacher to challenge them; I play "devil's advocate" (unfortunate nomenclature, considering the positions I'm forced to take being associated quite literally with the ultimate incarnation of evil) whenever I even have the willingness to engage controversial topics when they arise, which isn't often at this point. I need to better present my students with alternatives to consider, like focusing on the concept of dialectic with its thesis, antithesis, and synthesis. I might also improve my focus on the value of carefully considering opposing viewpoints, what Walter Lippman calls "The Indispensable Opposition." I need, though, for the spirit of open-mindedness, to retire the concept of devil's advocate and replace it with language that evokes a constructive cooperation, not adversarial arguing.

I'm not there to indoctrinate my students with my personal ideology, but I am there to indoctrinate them with democracy, with decency, with the process of intellectual inquiry and rhetorical deliberation, but there's more: I also want my students to develop a fighting spirit, and I will not achieve that goal without modeling the behavior I hope to encourage. I want my 
students to fight with ideas, but with the utmost respect for that fight, for the freedom they have to engage in it, and for one another, regardless of their opinions on issues like gun violence or vaccine passports. Right now, though, I am failing with regard to the fighting spirit. My spirit is plagued by the four sicknesses.

\section{Purging The Four Sicknesses}

One's $k i$ is not fixed. It can be strengthened, honed, bolstered. A strong spirit, a healthy spirit, is necessary to win. But one's ki can be afflicted. The four kendo sicknesses are fear, doubt, hesitation, and surprise, which all kendo players suffer. The only medicine for these sicknesses is keiko (practice). Only through rigorous training and experience can we be courageous, confident, assertive, and prepared for anything -- in kendo and in life, including teaching and composing. My $k i$ in the dojo and my ethos in the classroom can only progress by purging these four afflictions.

\section{Fear}

Much of the fear associated with kendo is the fear of being struck, of the physical pain. One reason that kendo has such a high attrition rate is that being whacked about the head and wrists can indeed hurt. Through practice and repetition, though, kendoka come to embrace the sting of a kote or men strike, so I have become somewhat inured. Still, strikes can hurt. Even after nearly a decade of dedicated practice, I still find myself mentally bracing when I bow in for oki-kote waza with "wood-chopping" beginners, knowing the ensuing sting, the sharp pain in the wrist, the hand, the forearm. I mask this fear, though, and I have learned to embrace pain. At least mild, voluntary physical pain.

Losing is also a fear. Shai is intense. It's fierce. But we lose so often in kendo that we're accustomed to it. I know players who have traveled and devoted a weekend to taikai, only to get whooped in 30 seconds in their first match and it's over. Fighting in a sanctioned tournament, one definitely doesn't want to lose, but one cannot fear losing. Ultimately, one must 
not fear being hit or losing an exchange. Both are universal truths: pain and loss. The only way to truly lose in kendo, though, is to give up, to quit, to forfeit one's fighting spirit.

My haunting kendo fear, though, is the future of my small dojo: the Bloomington-Normal Kendo Club. Our sensei is, from my understanding, the oldest active practitioner of kendo in the Midwest. $\mathrm{He}$ is a totem, and although "the old samurai is not dead yet," Nobu-san can't lead practice forever. However, I know that the remedy for this fear, too, is keiko. So long as we have a dedicated core of kendoka who practice fervently, we will humbly walk the whatever path because our passion for kendo will sustain us, when the winds of change blow.

My greatest fear for my writing? That I never take myself seriously enough to write with intention. That I never find my deepest voice. That I never write as freely or as creatively as I might hope. I've been reading a lot of Whitman lately. I have a 5 year-old named Walt. I read my mom one of his poems at random recently from my well-worn copy of his complete works: An hour of madness and joy. It was rather racy, considering I was reading it to my mom with my 9 year-old, Elvis, listening, too. But that poem is so absolutely beautiful and free, it made me afraid for my literary future. I fear that I may never have the courage to lose myself like that, to just go for higher aspirations, in writing or in life. I want to write just to write, for no ulterior motive, yet I want to write with deep, honest, clear-eyed intent. I've filled up notebook after notebook with personal journaling that's never intended to be impactful, to make a difference, to connect with my fellow sovereign human beings. I'm just freewriting along with my students during journaling time, somewhat rambling. I like it. It's good for me. I do indeed write a lot, way more than the average American man. However, I'm not as intentional, as aspirational, as courageous as I hope to one day become with my rhetoric and practice as a compositionist and a teacher.

\section{Doubt}

All kendoka have experienced doubt, especially when lining up against a superior opponent during taikai. I have a unique experience with this situation: During my very first 
Midwest Kendo Federation taikai when I had only been practicing for one year, I faced off against the winner of the top division -- the top player in the entire Midwest! -- for my match in our team battle against Battle Creek, MI. I had major doubt in my chances to prevail. After two passes, the match was mercifully over. Even though I lost almost immediately, I attacked with a full spirit. I did not allow my doubt to stop me from attacking. I went down aggressively, sword in hand, despite my doubt that I had any chance to prevail. I need to attach my composition and teaching of writing in a similar manner. I can't let doubts about my ability to persuade an audience or to inspire students spoil my willingness to try my best.

Kendo practice builds confidence one strike at a time. After that first taikai, during which I failed to record a single ippon in any of my three matches, I was faced with doubt. Would I ever score ippon, let alone win a match? I knew the only remedy for this self-doubt was keiko, so I dove into my practice with a renewed sense of purpose. I regret that in my nine years of kendo practice, I've only been able to attend taikai three times, but I have experienced success: I earned 2nd-place in the mudansha division at my second taikai, losing a hard-fought final match in overtime, and I won my first three matches in the sho-dan/ni-dan bracket at last year's taikai. I was able to enjoy these personal accomplishments because I overcame my doubt through rigorous keiko.

I have way too much doubt in my teaching efficacy, and I've let that doubt seep into my practice. I don't know if I'm inspiring or facilitating learning. My students test somewhat well, yet they're of a demographic that is inclined to testing well: not in poverty. I have a super-low poverty rate and very manageable class sizes. Most kids are from stable families. It's a rural gig. Not that rural poverty doesn't exist, absolutely it does. My point is that my students testing decently well doesn't really confirm for me that I'm succeeding. But I do have doubt. Am I inspiring lifelong readers? Am I helping them reach their goals, not only with college admission or career path but with being happy, kind, curious, and responsible? Do any of them continue writing? I have my students write in their journals quite a bit. Do any of them take that with 
them? Does writing ever help them process or heal? Help them plan or reflect? I hope so. But I have no way of knowing. The plight of the teacher: we plant seeds, tend to them, nourish them, hope that they take root and grow, then the little sprouts suddenly graduate and we often never see or hear from them again!

My doubt as a writer is largely associated with the future: Does my voice really matter? Do I have anything novel to say? Will I have the courage to seek out a community, and to write boldly and freely within that community? Am I even good at writing? I'm sure that I'm not alone in my self-doubt as a writer. I must find the courage though, and put in the practice necessary, to overcome this doubt.

\section{Hesitation}

Hesitation at the critical moment, at the opening, will result in defeat, every time. That doesn't mean we should dive headlong into battle without careful posturing, consideration, and much "conversation." However, once an opening presents itself, one must attack swiftly, with full spirit and conviction. In kendo, openings are subtle and sudden: hesitate and the opportunity vanishes. The moment of advantage happens so fast that we don't have time to think: we must simply react with an "unfettered mind." The only way to eradicate hesitation from my kendo, to stop thinking about reacting to or creating an opening and simply act accordingly, is through keiko. Just like with life, hesitating to seize an opportunity in kendo results in a missed opportunity. Through dedicated, consistent keiko, seizing opportunity, however momentary or slight, can become natural flow, not a conscious process, which is simply too slow in the lightning-fast world of kendo.

What about my hesitation as an ELA teacher? I hesitate to implement kairotic texts into the curriculum. I encourage my students to read the contemporary YA Lit for their choice-reading, but my curriculum is full of classics. I like them. Love them. But classic texts don't grab students' attention like modern YA Lit could. I also hesitate to contact parents as much as I should. I still feel like somewhat of a stranger to my students' parents, and I've been 
teaching all their kids for six years! Clearly they like me well enough because I am employed. I haven't really had much friction, but I wonder if that would change when I teach a book about police brutality or a book with a gay protagonist? I've kind of played it safe, yet l'm clearly getting antsy to challenge myself and my students on a deeper level. I need to stop hesitating with regard to this current moment in time. I need to embrace kairos.

As a writer? Well, I'm writing this right now. That's something. I write feedback to my students all day, every day. I journal with my students. But I don't write much by choice in my free time. I need to. Even though I embrace writing as my job, my vocation, and as a discipline, I want more from writing, on less of a transactional plane. The moment of truth will really come when I'm finished with my graduate degree. When I have no academic classes on the horizon, will I write just for the sake of writing? Will I set personal goals for my writing? Will I join a community of writers? How glorious it would be to write with people who actively choose to write! I work with students, and whether they like to write or not -- and many of them do like to write and are good at it, even those students -- are being compelled to write. They're writing for class. I've been moved by student-writing. I've shed a tear, honestly, but even those incredibly personal and well-written pieces are written for an academic purpose, like this thesis. It's just not the same. I've had some great experiences with the Illinois State Writing Project, which has given me a taste of an authentic writing community, but that's still an academic class composed of teachers, so it's ultimately a professional setting. I'm in my teacher persona at the Summer Institute, albeit my teacher-during-summer persona, but still. Not that that's not a real me, the teacher-me. He is. I am. But there's another writer in me whom l've yet to meet, yet to converse intimately with. I need to get in touch with that writer. Because if I get to know him, I'll be more likely to introduce him -- and his writing -- to others. My composition, though, must be rooted in documenting action. Mere speculation or opinion will not suffice. 


\section{Surprise}

Being taken off-guard is rarely comfortable in any situation, but it's especially detrimental in kendo. The last kendo sickness is "surprise." Again, the only way for one to be prepared for whatever may come during jikeiko or shiai is ample keiko. Every exchange is unique, though, so it's arguably impossible to be fully prepared for every possibility, from a technical standpoint because the possibilities are limitless. We have a saying in our dojo: "No battle plan survives first contact with the enemy." With this in mind, I have learned, in a way, to be prepared for all possibilities; it's a bit counter-intuitive: One can avoid being caught off-guard by not anticipating or expecting anything specific at all.

It comes back to the "unfettered mind": if I have no expectations, I will not be surprised by anything because I acknowledge that all is possible. I must stay vigilant in my focus on everything (enzan-no-metsuke) while being present in the moment, ready to feel the flow of the encounter and act as the situation dictates, without preconceived expectations. By being open to all possibilities, I am surprised by nothing. It's a work in progress, and I know that the only way to achieve an "unfettered mind" devoid of expectations is through rigorous keiko.

Surprise is the only kendo sickness that is potentially counter-intuitive with teaching because good writing is often surprising. I'm working with teenagers who are nothing if not surprising, sometimes it might be surprisingly predictable, other times predictably surprising. The point is that surprise comes with the territory, and it's often welcome. Surprise can be a problem, though, when it's manifested as a symptom of a lack of foresight, a lack of anticipation. If I get over my fear, doubt, and hesitation, and start to teach controversial kairotic texts, I can't be surprised when someone objects. I can't be surprised if students get heated or say something questionable or something I disagree with. I need to anticipate and communicate accordingly to whatever situation arises. I must remain tranquil. 
How is surprise a sickness for me as a writer? It has to do with the expectations I have of myself. If I surprise myself by sitting down and writing for an hour, purely for pleasure, then I'm not taking it seriously enough. I should expect that of myself. I shouldn't surprise myself like, "Hey I actually did some writing today." I need to be simply living up to my expectations for myself. Also, when I have a chance for feedback, to create with a community, I can't be surprised by criticism or praise. I should be comfortable enough in my own voice that criticism and praise, while both absolutely valuable, don't surprise me in the least. I know that I am a novice and that I am experienced. I shouldn't be surprised when an audience accepts my ideas, and I shouldn't be surprised when I'm rejected. But, at this point, I am surprised in myself when I write for personal pleasure, and I'm still surprised every time someone appreciates my writing. I admit that I'm surprised when my ideas are rejected, too. I still have an ego. But I have received some harsh criticism before, and it did take me by surprise. I didn't like it, but I pretended like I did.

I humbly composed haiku for the four kendo sicknesses, which I respectfully offer, despite my limited ability:

Sickness can be cured

No magic, only practice

The Way of the Sword

Inevitable

Is Death; abandon all Hope

Courage will ensue

All I can conquer

Relies not on circumstance 
But knowing I can

Flash, an opening

Arrives but will disappear

Blink, all vanishes

All is possible

Fill my mind with emptiness

Unseen becomes seen 


\section{CHAPTER III: KEN AND PEN}

Ken (剣): Sword

Pen (Noun): any of various instruments for writing or drawing with ink or a similar substance.

(Verb): 1. to write with or as with a pen; put down in writing;

2. To draw with or as with a pen

\section{Introduction: S(words): The Cutting Edge}

Words are the essence of humanity. What is our genius, our divine inspiration, if not words, especially the written word? I have an immense respect for the power of language, a power that we too often take for granted and abuse. However, our language and literacy also propels improved ways of thinking, knowing, and being. We write, therefore we can be. In a democracy, we fight vicious internal battles, so it is imperative that those battles be fought with words, lest we fight with swords. I do not want to keep sword and pen separate, though: my aim is to integrate, so what does the sword have to offer the pen, and what can the pen give the sword? What are the possible relationships between ken and pen, between swords and words, that can breathe life into our democratic institutions and energy into the cause of environmentalism?

The second element of ki-ken-tai-ichi is indeed the sword itself. The sword is the lodestone of kendo, the aura of which always transfixed me. The Japanese sword, the katana, was part of my awareness as a young boy, thanks to Leonardo of the Ninja Turtles and Shinobi on the Sega Genesis. I've always been fascinated by samurai, the duty-driven warrior class of feudal Japan. I cannot remember when I wasn't. I was always so enamored with Japanese culture, but my interest was always from afar, never as someone who actively participated; that is, until my 30th year. For instance, I loved The Karate Kid, but I never practiced karate. 
Perhaps my deep longing as a 9 year-old boy to be Daniel Larusso and have Mr. Miyagi for my sensei led me as an adult to an aged, sagacious Japanese sensei to teach and guide me. It appears the universe conspired to fulfill my existential need as a 30 year-old white American dude in central Illinois to have a Japanese sensei and sword fight. Still to this day, I'm drawn to the beauty and power of the katana like I was as a young boy.

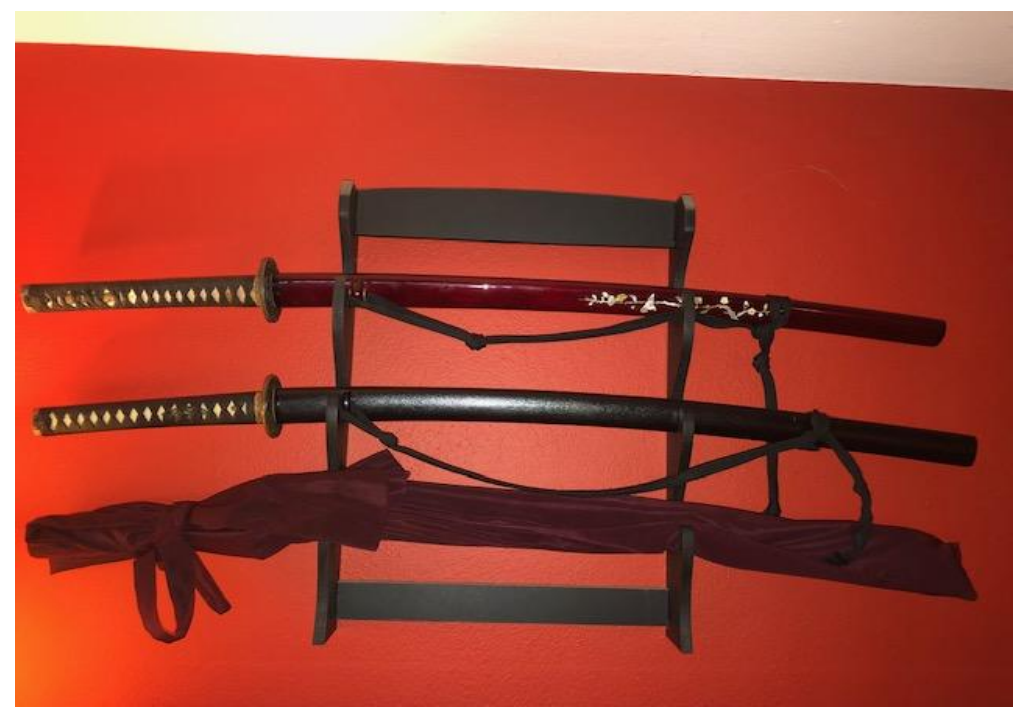

Figure 3: Katana, personal collection (2021)

I have likewise been hypnotized by the power of writing forever. I remember the first moment I was proud of being able to read. I've always loved reading and writing, and now I get to share that love and appreciation with my students. I have a book I wrote in 6th-grade, The Medallion, which I recently read to my son. I wish I had continued with more creative writing, but I have dedicated my professional life to literacy by teaching English Language Arts. Much like the martial art of kendo, literacy is a discipline, a mindset, and a formalized set of fundamentals that must be practiced consistently just to maintain, let alone improve. I hope that my writing continues to be forged, tempered, and sharpened by practice. My hands grip the tsuka, as my fingers grip a pen or tap the keyboard. In my academic and professional life, the pen is very much akin to the sword in my personal pursuit of self-discipline and contentment. 
These are the tools I rely upon to work towards being a person who is patient, kind, tolerant, and full of hope and optimism.

It wasn't just the Japanese sword that captured my awestruck wonder as a Midwestern boy in the 80 s; I was drawn to all swords. From the moment I saw the opening montage of Conan the Barbarian with the forging of the epic sword, I was fixated. I was just a boy with visions of wielding that immense sword in a quest of my own. To this day, I have the first issue of Marvel Comics' Conan the Barbarian hanging on my wall, a gift from my dad on my first Christmas. Who knew that he could have known me so well when I was only a month old?! Talk about foreshadowing. It's not a coincidence that Conan, in the absolutely classic Arnold movie, was initially trained with a Japanese-style sword because Japanese swordsmanship is the absolute pinnacle. My love of swords was destined to fix its gaze on the katana, the brightest star in the constellation of blades.

It's safe to say Star Wars had a major impact on my developing brain and my current obsession with swords -- and storytelling, too. The Jedi's lightsabers are based on Japanese swords, and the Jedi wield their sabers very much in the Japanese style. Darth Vader's iconic helmet is inspired by the samurai aesthetic. Apparently, I yearned to be Luke Skywalker even more than Daniel Larusso because I picked up kendo, the discipline that most resembles fighting like a Jedi Knight, but I regretfully never did get formally into karate, though, which I regret. Karate, however cool, doesn't involve swords, so I didn't feel compelled. Two teenage members of the BNKC are also huge Star Wars fans, so it's fun to have that in common. One is always talking up the glories of the Dark Side, trying to recruit me to the shadow world of the Sith. It entertains me so much to play along. Kids running with their imaginations never gets old. I just last week concluded Co-directing Illinois State Writing Project's Young Writers Camp, and Star Wars definitely came up more than once.

I used to enjoy being alone in the woods as a boy, searching for that perfect stick to forge with my imagination into a deadly glinting blade with which to ferociously attack the 
implacable trees. I was always on the lookout for a perfect curve, a steady taper, a stick with a natural tsuba (hand guard). I still, as a full-grown man, get so much enjoyment from stick-swords; just yesterday, when it was time to load up and depart from our family nature walk, my 5 year-old Walt wanted to keep the stick that had been his sword for the day. I explained it was a good stick-sword that had served its purpose and brought him joy, which was more than any stick could hope for. We respectfully bowed to the stick (as I bow to my iaito to open iai practice), thanked it, and chucked it into the trees. I spent ten minutes sword-fighting my 2 year-old Ernie with some foam toy swords today. He loved it. Not a day goes by in my life without some sort of sword action. If only I could say the same for composition. That is an insight I'm taking with me from this experience: I must choose to practice my composition in a manner similar to how I choose to practice kendo, which is whenever I can. Not because I must but because I choose to.

I have swords prominently displayed in my home. I have a mini-sword letter-opening set front-and-center on my desk in my classroom. I offered my wife a custom-made iato with purple suka and hamon that looks like the mountains and waves simultaneously. For me, a sword is much more than a sword. And likewise, a pen is more than a pen, considering that it has provided me with a career and security for my family.

\section{The Symbolic Power of Sword and Pen}

To those who aspire to a kendo fighting spirit, the sword is revered for its symbolic and literal power; the sword holds vaunted status in Japanese culture and is treated with the utmost respect. Distinguished scholar Inazo Nitobe describes the traditional status of the sword in his classic essay on Samurai ethics, Bushido: The Soul of Japan: "Bushido made the sword its emblem of power and prowess. When Mahomet proclaimed that 'the sword is the key of Heaven and of Hell,' he only echoed a Japanese sentiment" (117). A culture's relationship to the sword reveals its character and ethic. The respect for and centering of the sword is what drew 
me to kendo. Of course the sword has symbolic value: A man of the sword. Live by the sword, die by the sword. Fall on your sword. It's one of humanity's most potent symbols of violence and conflict. To cross swords. Yet it is also a symbol of honor, duty, responsibility, devotion, and sacrifice. Everyone knows that swords can kill, yet the sword can offer life, like it has for me with the discipline, routine, exercise, and friendship. I wouldn't go so far as to say kendo saved my life, but it certainly has improved the quality thereof.

I somewhat dislike using the sword as a symbol of the connection between violence and power, because violence is rarely undertaken with the honor imbued in the Japanese sword. But the sword does indeed remain that symbol of violence and power. However, despite the sword's immense symbolic power, there is another arguably stronger, more persuasive symbol, as expressed in the well-worn phrase "The pen is mightier than the sword."

Is the pen indeed mightier than the sword? Is intellectual argument more persuasive than physical force? (I wouldn't bring an essay to a gunfight.) We fight our battles within our democracy and in international diplomacy with the pen, with words, with rhetoric. The pen is mightier than the sword. Ideally, it's true. But does rhetoric hold more power than violence? This old saying, this priceless piece of wisdom that every literate human being has heard vouchsafes the heart of democracy and the essence of everything we hold dear in a modern humanitarian worldview that abhors violence -- but in a reality that drips with blood. American violence is at the highest level since the 70 s, and the world remains in conflict: Israel and Hamas just had another violent outburst, the Tigray region of Ethiopia is a civil war-torn humanitarian disaster, and the Taliban and soon-to-be on-their-own Afghan forces are still locked in a power struggle. The war on drugs continues with all its ravages south of the border and here at home. Can these problems be fixed by non-violent means, by communication and rhetoric, or will violence always beget more violence?

The pen is mightier than the sword. Imagine a world in which humanity wholeheartedly heeds this wisdom and ascends to a higher moral plane of non-violent cooperation. Ours might 
be a world of peace and prosperity for all. Ours might be the world of righteousness and opportunity we proclaim to strive towards in our imperfect American democracy and in our modern globalized world. The pen is mightier than the sword. Discourse can be our way out of perpetual conflict and violence. But violence is on the rise in our country with its attending rhetoric of meanness. I can't help but think of Cain and Abel. Humanity must rise above our history and our violence before we destroy ourselves and every living thing around us. We must use the pen to do so. The pen must light our way, but we will need to cut down what stands in the path to a sustainable humanitarian future. We need to change, much like the Way of the Sword has changed from preparing for actual lethal combat to a means of promoting peace and cooperation. However, there are limits to cooperation. Some ideas are too odious to let linger and fester, and they must be slayed.

I propose, therefore, that in our democratic fight for the future of our institutions and in our existential fight for the health of our planet, we must cut deep with our sharpened rhetoric. In the fight for righteousness, the fight for human dignity and personal freedom, the fight for voiceless species and ecosystems, the fight for our children and grandchildren's viability, the pen must be wielded as a sword without mercy to cut down the enemies of reason, decency, and progress. In today's cutting-edge world of immense creative and destructive power, we must forge our rhetoric as a razor-sharp weapon of truth and reconciliation. Our pen must be a sword that cuts down the evil of flawed logic and fraudulent ideas. We must seek out, confront, and attack racism, poverty, sexism, homophobia, xenophobia, corporate-malfeasance, and political chicanery. By sharpening our rhetoric and composition into indomitable blades forged of ethos, pathos, and logos, we can prevail over intolerance, fear, and hate. We can forge an honorable future for our civilization. The enemy is powerful and ancient -- greed and fear -- but we must fight with the pen. The pen is the sword. 


\section{Reverence}

In terms of ki-ken-tai-ichi, the sword is imbued with spirit and practice when one strikes. Without the sword, one is powerless to attack, let alone defend. Ken is the conduit through which flows one's intentions and form. Cannot the same be said of literacy? Multimodal literacies in our modern world of ubiquitous audio, video, and editing capabilities are the vessels we use to express ourselves and promote our ideas, along with more traditional genres of and methods of composition. If we are not armed with the requisite literacy skills, how can we even fight the good fight and engage an audience, let alone persuade that audience toward a position or ideal? If the sword is used to strike in kendo, then with what do we strike in the realm of education and democracy? Rhetoric and composition, in their myriad forms.

Composition is what can kill an opposing argument to win a debate, or cut through ignorance to inspire compassion or curiosity. But there needs to be willing and honorable participants in the debate and an open-minded audience to judge. This is increasingly challenging in today's discursive landscape, but there are good- faith intellectual combatants still out there, and our classrooms are full of students to deliberate the merit of arguments. The most persuasive compositionists extract their rhetoric from deep within, believing in and experiencing the communicative mission with utmost seriousness and duty, much like swordsmiths of Japan: "The swordsmith was not a mere artisan but an inspired artist and his workshop a sanctuary. Daily he commenced his craft with prayer and purification, or, as the phrase was, 'he committed his soul and spirit into the forging and tempering of the steel.' Every swing of the sledge, every plunge into water, every friction on the grindstone, was a religious act

of no small import" (Nitobe 119). My responsibility as compositionist and teacher compels me to pursue this level of reverence for intellectual inquiry and critical thinking about today's most urgent matters. I cannot casually promote the ideals of democracy and the imperative of sustainability; I must approach the forging of knowledge and the fighting against systemic 
injustice and environmental destruction with the zealous fervor and dedication of the Japanese bladesmiths of yore.

\section{Rhetoric: The Raw Material}

In my metaphor, rhetoric is the ore, the raw material, and composition is the willful steel forged from that ore. But what is the definition of rhetoric? That's debatable.

I unsurprisingly introduce my freshmen speech writers to rhetoric as "the art of persuasion." I emphasize that persuasion is not a dirty word, not akin to manipulation, coercion, or trickery. However, in our stormy cultural climate I suspect that the oft-invoked pejorative definition of rhetoric as political speech designed to dissemble, obfuscate, and twist reality to selfish, disingenuous ends is closer to the truth at this troubling moment in our history; essentially, Crowley and Hawhee's dispelling the misconception of rhetoric as "politicians' attempts to deceive" (1) in the very first paragraph of their excellent textbook Ancient Rhetorics for Contemporary Students isn't totally convincing for the layman perspective, as that misconception is what Americans' associate with the word "rhetoric" simply by how it's used in colloquial language. "Rhetoric" is a word that is used over and over in our political discourse, and it's almost always in a negative sense, which grossly undervalues the importance of rhetoric as a means of discovering the best course of action.

I might have laughed at Crowley and Hawhee's explanation of our democracy's need for rhetoric, if I had not been crying, because civil discourse is flatlining in American culture today: "Despite its difficulty, people who live in democracies must undertake productive argument with one another, because failure to do so can have serious consequences" (4). Of course, Crowley and Hawhee are correct about our need for responsible debate and respectful rhetors on each side of an issue, but that is not happening, and we are now stuck with the "serious consequences." Despite the return to semi-normalcy in our executive branch with the Biden administration, the previous administration's mendacity and bad faith shook me to the core, and 
the current big lie iteration of the Republican party forces me to consider questions that would have seemed preposterous not so long ago: Will our democracy eventually succumb to an minority-rule fascist theocracy? One thing is certain, though, and it's that Crowley and Hawhee are prescient: "When the quality of public discourse diminishes, so does the quality of democracy" (6). Truer words have never been written. Our democracy is in crisis, desperately in need of triage. During the tumultuous 2020 election and the disastrous aftermath that culminated in the Jan. 6th insurrection, I began to wonder if our democracy is already in hospice.

However, our study of what rhetoric is, has been, and can be does not have to be as degraded as our public discourse -- or our deeply fractured political and social landscape. The heart of useful rhetoric rests in what is possible in a specific moment: "Rhetoric is the art which seeks to capture in opportune moments that which is appropriate and attempts to suggest that which is possible" (Poulakos 37). I appreciate the emphasis on the "opportune moments" in this definition, which relates closely to the rhetorical concept of kairos. What might be urgent and full of import one moment might be inconsequential the next. Taking a pulse of the culture and its challenges in a specific moment of time is of the utmost importance to this definition of rhetoric. Then we can undertake stasis inquiries to find the best course of action for the greatest number of people.

Or is rhetoric simply a natural state of being, something that is as much a part of the human experience as breathing: "[D]efining humanness and defining rhetoric are hardly distinct tasks. What makes us human is our culture, which is founded in our unique form of symbolizing, our language, which is in its very nature rhetorical as it goads/gods us, moves/motivates us, makes us social, cultural (non-)animals, allows us to compose ourselves humanly. The study of language, culture, discourse, rhetoric, and humanity is one" (Coe 47). This definition makes sense because we are immersed in culture and language from the day we're born, and what is life if not a long series of decisions, of deciphering the best course of 
action to all the conundrums that face us at all times. We're constantly seeking out the best course of action, or defining and refining who we are and what we value. From this perspective, rhetoric is life, which leads to another definition: "Rhetoric is defined by what it does" (Coe 48). Rhetoric can build or tear down, inspire or deter, inspire joy or instill dread. All that we are and all that we do, that is rhetoric.

\section{The Life-Giving Sword or the Death-Dealing Sword?}

We've forged ideas with the written word for thousands of years, crafting those ideas into books, which are literary swords that could and still can be used for justice and righteousness or for deviousness and corruption. Just like the sword might be used for good or ill, so too with the pen: "There are times when ten thousand people suffer because of the evil of one man. Therefore, in killing one man's evil you give ten thousand people life. In such ways, truly, the sword that kills one man will be the blade that gives others life" (Yagyu 9). Destroying a flawed, disingenuous, or deceptive argument will intellectually sting or diminish the reputation of the purveyor of the ignominy, but it will disabuse the audience of a potentially harmful position or idea. Slaying a bad argument or decentering a prejudiced narrative enhances the vitality of logic and truth. In this way, rhetoric and composition is indeed a life-giving sword. But, as we know all too well after the relentless, malicious rhetorical onslaught of a half-decade of incendiary, indecent, and mendacious presidential tweets and bad faith from the right-wing and its media echo chambers, rhetoric and its compositional multimodalities of our powerfully digitized world can be weaponized for evil.

We are at an inflection point for humanity -- and for the entire universe, as far as we know. What we're currently doing to our planet, its ecosystems, and its species -- and to ourselves -- is unsustainable. This cannot go on. We cannot allow it. Our consumer culture must be reimagined. We are tiptoeing on the cutting edge of time. The future is up to us right now. This is currently happening. We are the ones who must look ourselves in the mirror. We 
must use rhetoric to forge a society and an economy that doesn't kill and destroy everything in its path. Our transportation system is poison. Our food system is poison. Our clothes, buildings, devices, poison! I look at the clock, and it's growing late. Our time is running out to figure this out.

Is it not too late to save ourselves with rhetoric? Can we evolve our thinking and decision-making as a species? I hope so. I want to believe that we can, but I do not know. Yet I hope that our rhetoric and composition be the sword that slays war, that decisively cuts through the obdurate armor of fanatical religious zealotry, outdated fundamentalist ideology, jingoistic chauvanism, and xenophobic race-baiting that drives us mad with civil and state-sponsored violence. May the reflecting light that catches the blade glint and shine as it cuts through ignorance, greed, and hate, blinding those who would disfigure our social and scientific progress with ignorance and fear. The dueling swords with which the battle for minds -- and the future -is fought are multimodal compositions. So, today, what is the cutting edge of the sword, the "key to Heaven and Hell"? What actually cuts? Good ideas that reach an open-minded audience. We need rhetoric to find the best ideas and the most efficient ways to reach the audience.

Those who create, those who resist destruction must convey ideas of a peaceful future, suddenly evolving beyond and atoning for our history of oppression and bigotry. I've heard this hoped-for revolution of ideas to come referred to as the "wisdom revolution." The idea is that this wisdom revolution will occur suddenly. It took thousands of years for the agricultural revolution, hundreds of years for the Industrial Revolution, decades for the digital revolution. Maybe the next revolution for our human civilization, catalyzed by the power of rhetoric and the accessibility of multimodal composition in this information age, will be a wisdom revolution. We can forge our rhetoric into compositional katana wielded for justice, redemption, and humanity's salvation from destruction. And we can use this blade to cut down climate-deniers, anti-vaxxers, corporate overlords: "It is missing the point to think that the martial art is solely in 
cutting a man down. It is not in cutting people down; it is in killing evil. (Yagyu 12). We must kill evil with the cutting edge of ideas on the shin-ken of composition forged from the steel of rhetoric.

On the literary front, kids are reading fewer and fewer long-form texts by the day. Books are disappearing from the eyes and minds of the masses who are sedated by social media and streaming services, yet these digital spaces do not have to be conduits of intellectual degradation. The duel must be fought there, too, by skillful compositionists and content creators who meet the audience where they are, and that is increasingly online and visual.

In today's digitized world of online spaces, the "cutting edge" is absolutely multimodal. The audience is online. Our modes and forums of discourse have evolved rather suddenly. This digital revolution encourages all to participate in not only consuming content but in creating and sharing. This is empowering and democratizing composition and discourse. In the past, audiences of print were subject to the intellectual arbitration of editors and publishers. Distribution networks were tightly controlled, but to be published came with embedded credibility. Not everyone could wield the power of the pen. Professional writing was a cultural and intellectual knighthood, a literary warrior class that behaved within the bounds of certain ethics and codes of conduct. But our contemporary brave new world in which everyone can publish, everyone can offer public opinions and ideas, has somewhat backfired. It has unleashed a frantic barrage all across social media. However, the cuts from online content are too often unclean, the blade is poisoned. The wounds fester and burst, and we are left with a body politic that is delirious with fever, raving and stumbling about, blind with the poison coursing through its veins, screaming, shouting, sobbing.

Rather than complain about the state of social media, I need to participate. I eschewed social media early on, but now that l'm craving an outlet for my voice and a way to harmonize my ethos, composition, and activism in a public space, it's becoming rather clear that I need to utilize these multimodal spaces. 


\section{Many Swords: Multimodality, Genre, and the Rhetorical Situation}

Composition is multimodal. The written word remains of supreme import yet our composition extends into the visual realm, as well, with sophisticated cameras and editing software readily accessible to most citizens. Our exciting reality is one in which visual and aural rhetoric can and should be wielded for many rhetorical situations. Preparing my students to be literate not only with the written word but with visual and auditory rhetoric is essential for preparing them to successfully navigate an evermore robust and demanding communicative landscape.

In composition, rhetoric is the steel that is worked into a communicative tool, a modality that can be shared with an audience. The modality of composition itself -- that is the sword of communication. Composition can be used to attack ignorance but must be wielded skillfully. Training my students to compose in a multimodal world is imperative, and I need to improve by utilizing multimodalities with project-based learning as the powerful tools they are. I have found guidance in Multimodal Composition: Resources for Teachers (Self, 2007). Despite the fact that online applications and resources have evolved dramatically since this book was published, the theoretical framework for teaching and implementing multimodal composition remains valuable, including the five-point articulation of the importance of multimodal composition the begins with: "In an increasingly technological world, students need to be experienced and skilled not only in reading (consuming) texts employing multiple modalities, but also in composing in multiple modalities, if they hope to communicate successfully within the digital communication networks that characterize workplaces, schools, civic life, and span traditional cultural, national, and geopolitical borders" (3). It is imperative that I teach my students to create and compose with multimodalities, so I must compose in those ways myself. Again, my passive non-participation is a hindrance to my expertise and proficiency with the multimodal tools. I must compose to learn, so that I can better serve my students. 
An essential question that compositionists must ask at the outset of a project is, "What's the most effective combination of modalities for reaching my intended audience, and which modalities does that audience best engage with and positively respond to?" There are different contexts and purposes for composition, from engaging with professional academic communities via white paper to videos intended for a general public audience on social media. The mode that best communicates varies from situation to situation, so a compositionist must choose the appropriate "pen" for each unique rhetorical situation. The genre in which one communicates matters, too. We must choose the appropriate tool for the specific task.

The Way of the Sword also relies on different swords for various contexts and tasks, too. I have five distinct swords that I use in my practice. The sword that is used most often during kendo practice is the shinai. This is a sword composed of four bamboo slats held together by leather rigging called nakayui. The composition of the shinai allows for flex and bend, so that it has sufficient give when striking the opponent's head, wrist, torso, or neck. No matter the sting on the wrist or the ringing in one's skull after being hit with shinai, one can take solace in the fact that bones are always stronger than the bamboo slats of the shinai. We check our shinai for splintering or cracks before every practice to ensure the integrity of our swords. If not properly maintained, the splinters from a frayed shinai can be dangerous, so we have a duty to care for one another's safety. This pertains to spirit and rei-ho (etiquette). Fighting with swords that do not cut, that do not injure is imperative. They sting. They can bruise. But in ten years, I have not seen someone injured by shinai. With rhetoric, however, do we affirm similar humanity through mutual well-being and fitness, or do we too often intend to injure with our words? Because words can cut deeply. Although we should aim to kill bad ideas, we should protect each other, even our ideological opposition. We have to live together. 


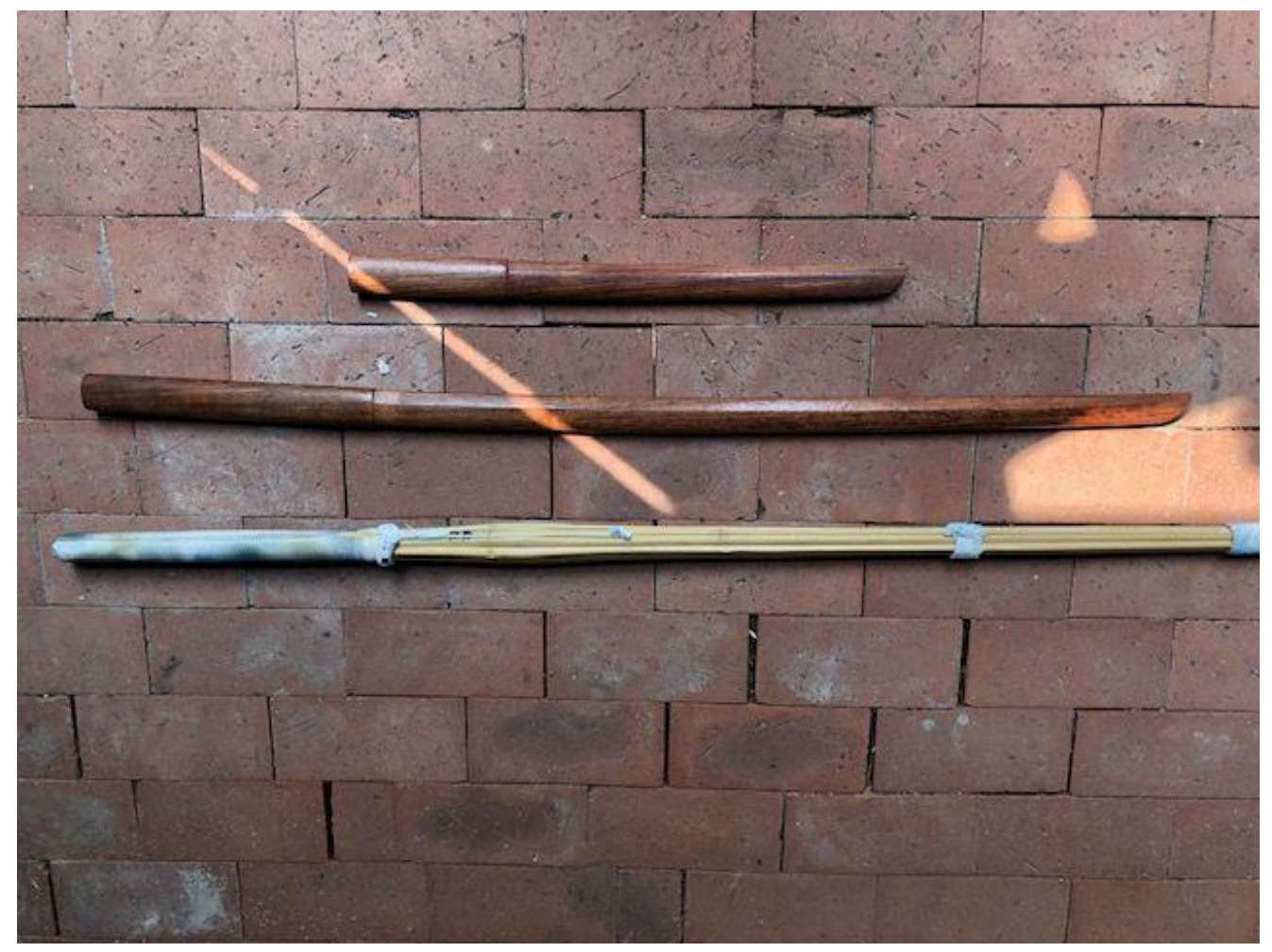

Figure 4: Bokken and shinai (2021)

My sword bag also has bokken, which are solid, hardwood swords. These swords have no give, and can be dangerous as blunt instruments, but we do not ever actually hit with these swords. Bokken are used for kendo kata, which are choreographed encounters in which the uchidachi leads the shidachi in routines that emphasize fundamental forms and movements. Kendo kata has thirteen total forms: ten in which both uchidachi and shidachi both use odachi (standard length swords) and three in which shidachi uses a kodachi (short sword). My set of bokken was handmade by a fellow kendoka who graduated with honors from Illinois State as a studio art major. These swords are special because they were crafted by a close friend who has since moved permanently to Japan. Nobu-san offered a traditional Japanese tea ceremony at the dojo for Dan-san before he moved away, and I was honored to experience such a formal traditional Japanese ceremony. I am honored to practice with swords crafted by his hands. 
Although distinct from kendo, it's worth noting that I also practice iaido, which is another distinct practice of Japanese swordsmanship. For this discipline, I use iaito, which is an actual sword with a metal blade and saya (scabbard). laido is also kata-based, but it's all individual, imagining that one is being attacked in various ways and responding accordingly. laito, though, are not swords used for actual cutting: the edge is dull. It will not cut, so iaito are practice swords with which one can make a mistake and not suffer serious injury. They're still pointy, and l've definitely drawn some blood with poor noto (re-sheathing), but they are swords designed for practice. lato are also works of art. Mine was forged and customized in Japan, as was my wife's. We practice iaido together, which brings us closer. We love that time together in the dojo. That time spent together using different swords for different practices is vital and relates closely to ideas in an essay in Multimodal Composition, entitled "Collaborating on Multimodal Projects," which is clearly valuable to my plan to implement project-based learning: "Collaborators can also give each other the emotional and intellectual support needed to persist in working with new modes and technologies" (41). In the Way of the Sword, we support each other in our various modalities, and I want to enhance that spirit of interdependence in my classroom through this use of multimodal, multigenre collaborative project-based learning.

I have one additional type of sword in my collection, yet this sword does not come down from the wall very often: shinken, the "live blade." This sword cuts; it's dangerous. This is the sword best known as katana, the legendary blade of the samurai. The shinken does have practical value to my swordsmanship beyond being a symbol and a decoration: tameshigiri (test-cutting). In old Japan, all samurai carried razor-sharp swords. Kendo was preparation for mortal combat. All the practice was for the occasion to actually fight, kill, and die. Thankfully, I will not be called upon to use my sword-skills in actual life or death battle, but sometimes the world of rhetoric feels rather life and death.

Too often today, our rhetoric is malicious in its neglect of etiquette and hurtful intent. By using harmless swords in kendo, we honor each other in our mutually-dependent struggle for 
progress and understanding. Yet, so often, rhetoric dishonors the opponent and hurts in the real world. The manner in which we communicate reflects who we are and what we stand for. Will we rediscover a way to temper our American rhetoric for the mutual benefit and well-being of all, or will our communities continue to devolve and decamp into factions that utterly despise each other? Because that's where we are headed. We scarcely have any respectful intellectual combatants from the right-wing who agree to engage cooperatively to fight against our shared exigencies. The divisions are bitter and getting worse. I'm clearly a liberal, so I'm situated with a certain perspective, but the insanity of the right-wing rhetorical style is really getting to me. All of the name-calling and constant stoking of fear and anger over the culture wars is just get-wrenching as it distracts us from working together to address our most dire exigencies.

Republican political rhetoric is obsessed with and aggrieved by wokeness, cancel culture, critical race theory, and abortion. Seriously, why can't they just tone down the nonstop outrage? As a teacher, the obsession over critical race theory and the push to pass laws against teaching about America's racist roots, history, and systems is absolutely chilling. The speech that the former President gave last 4th of July before Mt. Rushmore in which he denounced the government schools that are indoctrinating children to hate America absolutely made my skin crawl. America has a sordid history which we've yet to officially acknowledge, reconcile, or redeem. Can we wield our razor-sharp rhetoric as a life-giving sword that conquers our darkest impulses? Or will malicious, wanton rhetorical violence continue unabated, even encouraged, and will that spill over into violence in our democracy? (On a positive front, we did initially agree upon a bipartisan infrastructure deal today, so there's some evidence of sanity, but it doesn't erase fealty to the big lie, nor does it absolve the half of our body politic of its mass delusions and willful spite for core institutions, particularly elections, legacy media, and academia.)

Which is mightier in America, the Pen or the Sword? Which is mightier in history? My deepest fear, right now as an American, is that the fatal intent of our rhetoric will extend into 
actual violence. I am honestly terrified of the 2024 election if something doesn't change between now and then with how we speak to and about each other. It's a tough question about the Pen or the Sword, which holds the true power because it is the wrong question; it's not one or the other: the real power lies at the intersection of both Pen and Sword. Are they even different, distinct? Is not violence rhetorical? Of course it is. It's perhaps the purest form of rhetoric. It's certainly the most belligerent. That's the beauty of kendo, though: the agreed upon violence that, in shiai, ends in one side winning but with both sides intact for the next skirmish. That mutual interest and respect at the heart of kendo (of any combat sport) is sorely lacking in our public discourse. If we could get back to stasis inquiry, back to using rhetoric as a navigation tool, a wayfinder for us to inquire, debate, and chart a navigable course, we just might have a chance to stop bickering on purely partisan lines in congress, on social media, and in life. We have massive problems that will take cooperation to mitigate or solve, and we cannot continue to fight mercilessly with each other in the culture wars. We just can't. We need to embrace the freedom we profess to revere and accept that people have the right to be who they are in America. Let's move on to saving our future, a future that we must all share. 


\section{CHAPTER IV: TAI AND ACT}

Tai 体 (noun): body; physique; posture, shape; form; style, substance; identity; reality; field Act (noun): 1) anything done, being done, or to be done; deed; performance:

2) the process of doing;

(verb): 1) to do something; exert energy or force; be employed or operative:

2) to reach, make, or issue a decision on some matter:

\section{Introduction: "One Who Moves Never Grows Cold”}

Every kendo dojo has a shrine to which members bow respectfully (shinzen nitashte, rei!) before and after each practice. That bow is an important symbolic act that sanctifies the space we are about to use for our edification. It's an act that, along with bowing upon entering and departing from the dojo show a reverence for the space itself. (I wonder how to do this for the classroom?) Each dojo's shrine is unique, but a common centerpiece is kakejiku, a wall-hanging scroll that is inscribed with a phrase, written in kanji, which serves as the dojo's mantra. At the BNKC, our kakejiku is inscribed with the phrase: One who moves never grows cold.

I've unfurled, hung, bowed to, lowered, and rolled our kakejiku, gently replacing it in its box hundreds of times over the past decade of practice. Each time, I handle this precious scroll with the utmost care and respect. A symbol of our dojo, its phrase (beautifully rendered in handwritten calligraphy by one of Nobu-san's oldest friends in Japan) is the essence of

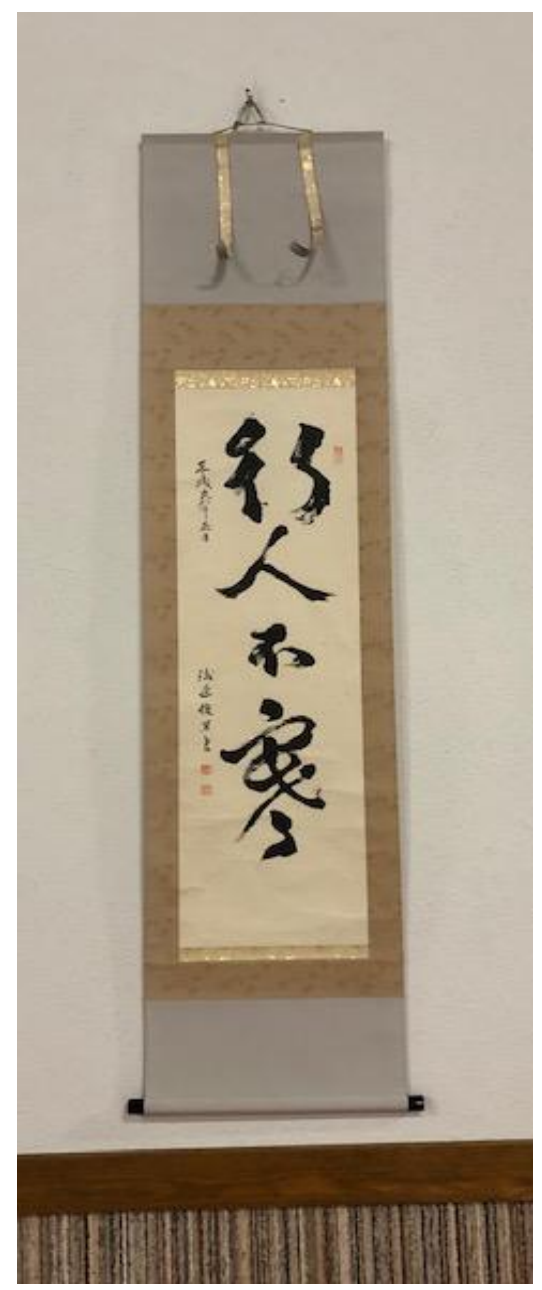

Figure 5: Kakejiku, Bloomington-Normal Kendo Club (2020) 
our dojo's ethos: that, in life, we must act in order to progress and avoid the stiffening cold of physical stagnation and spiritual apathy. One who moves never grows cold. This concept is both a challenge to keep pressing onward, and a philosophical approach to my studies and practice -- in the dojo, yes, but also in the classroom and my space as a writer. The potential within this concept is physical, even with regard to the intellectual and creative acts of teaching and writing. I must act to fulfill my commitment to this guiding principle of my dojo and sensei. Staying active and engaged in spaces and communities is essential for me to "never grow cold." I must harmonize my tai, my physical acts, with my spirit and sword to attain ippon. Progress on my journey, my shugyo, can only be achieved through action.

With regard to kendo, I'm compelled to understand tai in physical terms, although action can arguably exist on planes other than purely physical. Is thinking an act? Surely listening is. The fact of the matter is that words are powerful, yet a physical act is always manifest in the words, if only in the physical act of writing itself. Words represent action and call to action. The connection between act and literacy is essential. Act, action, active, activate, activity, activist. What is the value of an idea if it is not supported by or contributing to an act, an action here in the physical realm? Why compose if not to inspire action, in oneself or in an audience.

As I consider the tai of teaching, writing, and kendo, I seek insight into the following questions: What can I learn from kendo's concepts and demands of tai that can empower writers and teachers of writing in our democracy? How do kendoka train using our bodies to develop our personal style, identity, and values, and what insight can that provide for rhetoric and composition? How can one's physical presence and activity be used to create personal meaning and identity? How can teachers and composers synchronize our physical beings with our ideological spirit $(k i)$ and compositional modality (ken), just as a kendo player strives to unify spirit, sword, and body to make a strong, beautiful strike?

I seek answers with a reflection on the value of taking action, vis a vis engagement with communities and utilizing space, both physical and virtual. The primary mode of taking action to 
progress one's kendo is simple and obvious: going to practice; hitting the dojo. How we approach practice and the resulting quality thereof is worth investigating closely. Might my understanding of and experience with developing my kendo ability through focused physical practice also serve as a path for developing my rhetorical and compositional skills, as both teacher and writer? And how can the practice of my teaching and writing apply to my kendo study, particularly concerning the nature of the student-centered classroom?

\section{Practice: The Essential Act}

Kendo practice is keiko (稽古), which Nobu-san explained to mean "learning from oldness." Keiko is rigid yet fluid, invigorating yet exhausting, empowering yet humbling, analgesic yet masochistic. It is highly structured chaos and improvised routine. Kendo begins with keiko and ends with keiko. We have a saying in our dojo: "There is no magic, only practice." Keiko is the way of progress not only in kendo but in any endeavor, the only path to ascend. That begs the question: What is progress in composition? As a writing teacher? Ultimately, progress as a writing teacher is directly related to my ability to inspire compulsive curiosity and courageous open-mindedness. As a writer myself, progress is academic achievement, sure, yet it's more than that. I'm not exactly sure what. I am certain, however, that no progress can be made without physically performing the act, over and over and over. Year after year. I must continue to write. I must continue to teach.

In my shugyo, practice is the only way. The importance of practice is clearly common knowledge: "Practice makes perfect." But what is it about the quality of kendo keiko that might be of use in my writing and teaching? Kendo practice is fundamentally collaborative. One cannot practice waza or ogi-waza alone. Progress without the presence and support of a community is virtually impossible. This spirit of community and mutual reliance is vital to kendo, and this mirrors the symbiotic relationships in the worlds of teaching and of rhetoric and composition. A teacher needs students and a writer needs a reader. As a public school teacher 
in America, I have a duty to contribute to preparing responsible citizens who are prepared to participate in our communities.

Taking action to inspire young members of our democracy to celebrate their literacy skills and generate meaning by writing and drilling the postures and forms of striking technique in Japanese sword-fighting both must be pursued with community. The kendo community, albeit small, is tight. Everyone is invested in the practice. We pay dues and devote personal time. This is fundamentally different from being a high school ELA teacher, when many of our students are engaged and enthusiastic but others can be hard-to-reach, disinterested, or indifferent; all, however, are rather compelled to be there. The practice is of a different quality when young people actively choose to devote time to their writing and creativity.

Having just completed my first year as Associate Director of the Young Writers Camp at ISU, a position I hope to continue, I'm interested in community building for young writers that goes beyond the academic classroom. An inspirational example of the power of building a writing community with young people is the Writing Our Lives (WOL) project, based in Syracuse, NY -- a community writing program aimed at supporting the writing lives of urban youth. This program's power is derived by bringing young writers together to practice, to express themselves, to make meaning of their experiences and existences: "At annual writing conferences, yearlong after-school programs, and regular Saturday writing events, young people come together to tell their stories and write about the issues that are important in their communities" (Haddix). I admire the mission of this project in getting young people engaged in the issues through writing in a non-academic setting.

The WOL project is action-based. It's about coming together to promote positive change through community outreach and youth activism: "We draw on our personal narratives and conversations to share an example of what happened when a youth writer called for social action and change, when her call was heard by supportive adults in her community, and when her writing contributed to moving forward a school reform agenda" (Haddix). Propelled by 
occupying the virtual spaces of social media, WOL was able to activate a physical community with which to practice and progress: "During each session, students engaged in a variety of topics and writing genres, including hip-hop music, dance, creative writing, and cartooning. Students also read mentor texts by revolutionary leaders such as Malcolm X, James Baldwin, Assata Shakur, and Angela Davis" (Haddix). A community that practices together, that progresses together, is stronger together.

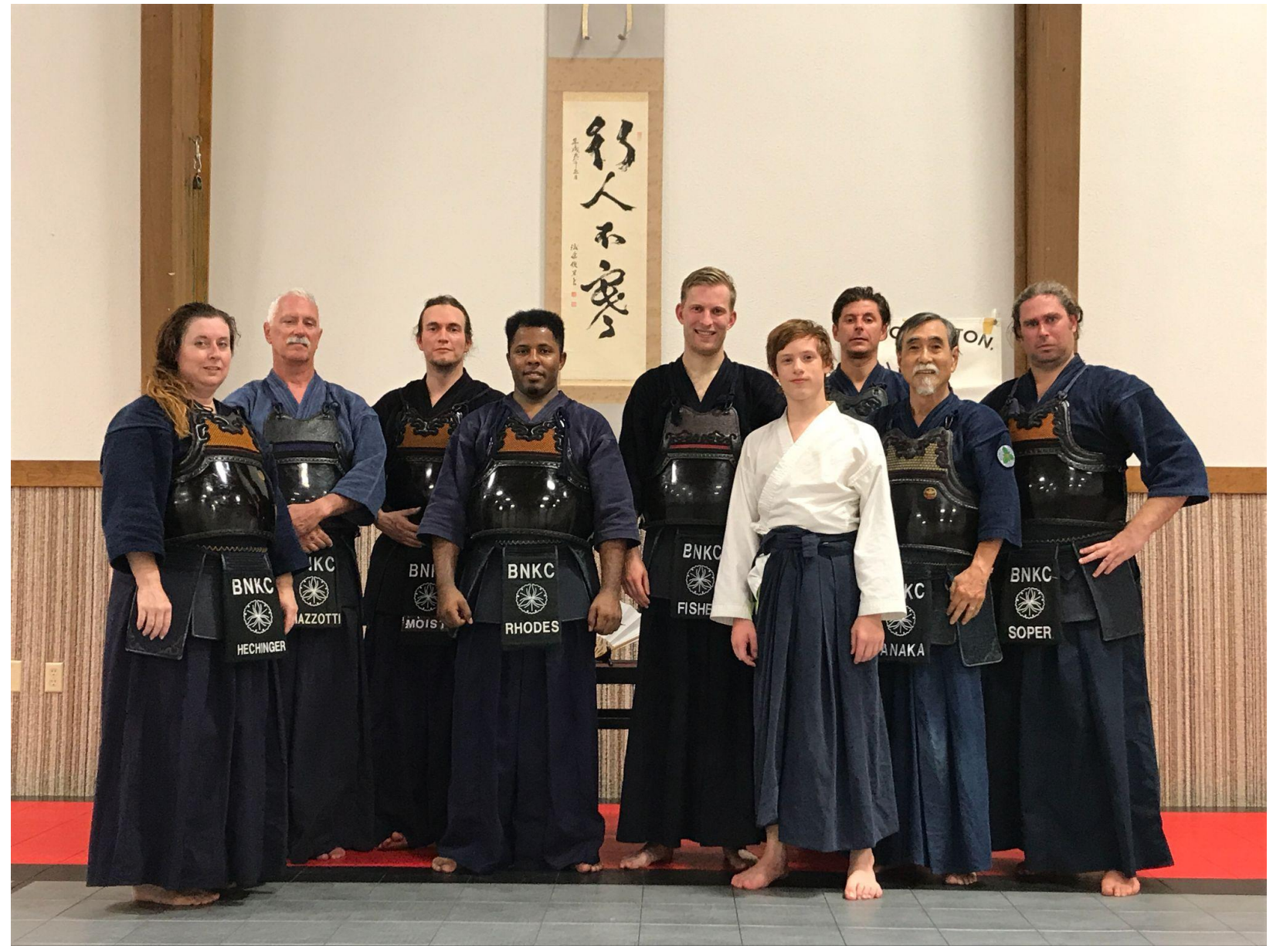

Figure 6: Farewell keiko, BNKC (2016)

\section{The Three C's}

Nobu-san, at kampai early in my kendo journey, took me aside, looked me square in the eye, put a hand on my shoulder and described his concept of the "three C's" in relation to keiko: 
consistency, commitment, and communication. To get the most out of my kendo practice, he instructed that I must be mindful of these three crucial elements, which also offer valuable insight into how to continue to improve my actions as a writer and teacher.

\section{Consistency}

Consistency is highly valued in keiko. Daily kendo practice is not unheard of, especially among retired, high-ranking kendoka. I strive to practice twice a week: week in, week out, year after year. I've been practicing kendo for nine full years, at this point. One must be consistent if one is to harness the power of fundamentals to, ultimately, develop one's unique style into something formidable, exhibiting both strength and beauty. This value of practicing consistently is imperative for any skill, including teaching and composing.

Consistent practice builds stamina and muscle memory. Kendo beginners are absolutely wiped out by the end of keiko -- some are exhausted after a few waza (technique-specific drills). By the end of most practices, I am spent, sucking wind, struggling to stay focused, to retain my posture and form, and keep some meager semblance of kiai (vocalization of spirit). However, this is not the case for sensei and other high-ranking kendo players; of course, they exert tremendous force and energy, but they make it look incredibly effortless through the years of rigorous keiko. Some high-ranking sensei seem to possess supernatural powers: never tiring, never wavering, never revealing pain or haste, gliding smoothly. Everyone else in the dojo is ready to collapse, but sensei could go another two hours because he has trained his body to relax, to breathe properly, and to move simply and efficiently. If you've ever been in a sword fight, even one reckoned by bamboo, you know how difficult it is to relax, breathe, and economize movement. This calm self-assuredness only comes with consistent keiko. Shortcuts do not exist. There is no magic, only practice.

Writing consistently builds physical stamina, too, and I include the mental task of simply staying focused as a physical skill. This is why I increase my young students' writing time as a 
semester progresses: because they're building up writing stamina and expanding their writing-attention spans. Practicing consistent writing habits is essential for elevating rhetorical and compositional form, posture, and confidence. Ideally, a writer writes every day. I am yet to attain this ideal. As a teacher, I take pride in my students actively writing every day during class.

Writing consistently has another benefit beyond building stamina: each writing session produces an artifact, a record, a verifiable quantity of writing. To find the diamond, one must sift through metric tons of earth. To produce a composition that moves an audience, one must create a veritable mountain of writing, one stone at a time. One day at a time, through practice.

Performing the same waza practice after practice creates muscle memory and ingrains the fundamentals. As one practices repeatedly, the movements and form become second-nature. One eventually doesn't have to actively focus on proper kendo form and posture; it is internalized. When one reaches that level of natural movement, when the fundamentals of kendo have been imprinted on the muscle fiber, the fun really begins: when one can act and react with consciously thinking about acting and reacting, one's unique style can emerge. This is what we refer to as "the unfettered mind," an ideal articulated by Buddhist monk Takuan Soho in his 17th-century philosophical treatise on the the Way of the Sword: "Regardless of what a person does, when he engenders the mind that thinks about doing something, the mind stops in that thing. Therefore, one should engender the mind without a place for it to stop: "If the mind is not engendered, the hand will not move forward. Those who when moving engender the mind that ordinarily stops in that movement, but do not stop at all in the course of the action -- these are called the accomplished men of all Ways" (Soho 25).

Consistent practice seeking an unfettered mind is imperative in developing fluent young writers. The goal must be for students to feel confident in their language, not a language I prescribe, although I do note the existence of a "standard" English that persists in various institutions; students have a "right to their own language" and should be encouraged to build 
confidence naturally with their authentic voice. That fluency, that confidence in the flow is everything. Once the fundamentals of their written expression flows without conscious thought about conventions or rules, without stopping the mind, the meaning-making of expressive composition becomes unfettered, and we open the path of writing to learn and writing to make meaning. Confidence opens ways of deeper levels of writing and inquiry, like analyzing rhetorical situations and deconstructing the characteristics of genres. By practicing these more advanced rhetorical activities and compositional considerations, students will have tools to communicate more effectively. The forms and postures of scholarship and research in the academy can also only be acquired only through practice.

In my practice, I must never forget the "beginner's mind." We begin with the basics and progress into the higher spheres, ultimately seeking that place of "no mind" (mushin) where our expression simply flows, like water through the bends of a winding river. But, to be like water, there is no magic, only practice.

Writing at different educational and professional levels with various audiences takes the requisite skill sets. It's a cumulative art. A writer cannot rank-up, just like a kendoka cannot rank-up, until competence in certain skills are demonstrated. Many of my freshmen students still struggle with usage, grammar, and punctuation. The only way for these young writers to improve is to practice. Many students have solid command of writing mechanics, but struggle with concision, clarity, and voice. The only way to improve is to practice. A graduate student pursuing a Master's in rhetoric and composition might struggle with sifting through a decade of practice, looking for gems of truth. Practice is the only answer, but consistent practice is not enough: to pursue the way with any success, I must also be committed to the practice.

\section{Commitment}

Commitment relates to composition in terms of purpose and ownership. I've seen a kendo player just going through the motions; he was staring right back at me in the mirror. 
Writers, too, can just go through the motions, uninspired by one's own ideas or hopeless that a genuine audience will ever emerge to communicate with. Writers can get listless; writers are susceptible to ennui. Writing just for the trash bin will always be part of it. However, when I practice my art with purpose, with commitment to the quality of my time and effort, I can attain new heights of the unfettered mind, achieve flow, and emerge with a worthwhile artifact.

My purpose as a teacher is to inspire this requisite commitment in my students, not simply expect or demand it. This is another example of why the ethos of the student-centered classroom (as previously noted in the ki and ethos chapter) is so vital to a thriving writing classroom that engenders committed students. The more actively involved students can be in the nature of their writing practice, in the choice and cultivation of the rhetorical situations in which they locate themselves, the more authentic and earnest their writing endeavors become. How to do this with action? Teaching for a Living Democracy offers an excellent model, along with great encouragement and inspiration for teachers who seek committed students through action.

Commitment to one's purpose, though, necessitates a certain seriousness and attaches importance to practice. Takuan notes the necessity of seriousness, too: "The meaning of the word seriousness is in holding the mind in check and not sending it off somewhere, thinking that if one did let it go, it would become confused. At this level there is a tightening up of the mind and not an iota of negligence is allowed" (Soho 27). Yes, writers should write consistently every day, but not if we are not serious about it. One must practice intent on progress toward some goal. Nobu-san has always encouraged me to practice with intention: to reflect upon -- and get feedback about -- my ki-ken-tai-ichi, so that I might mindfully practice with intent the next time I bow into the dojo. Feedback and constructive criticism are of paramount importance to establishing a serious commitment to practice. I must always remember this importance of seriousness in my actions as a teacher. A teacher just going through the motions is a tragedy. I know I have. 
Consistent practice is a waste of time without commitment: think of the kid who's forced to practice an instrument that she's not interested in, or a student who actively dislikes writing and resists, squandering his writer's voice and perspective. What's the point? Commitment is imperative to progress. One must actively seek practice, actively choose progress, actively overcome limitations. Commitment must also be actively communicated to take root and grow, both to oneself and to the wider community to which one belongs.

\section{Communication}

Communication is essential for development in the dojo: communicating both with one's fellow kendoka -- and with oneself. As noted, kendo is communal. One cannot fully practice alone. Just like a rhetorical situation doesn't exist without an audience, kendo doesn't exist with at least one partner: uchi-dachi (student) and shi-dachi (teacher) are essential. Without moto-dachi (receiver) to strike during waza practice, there's no kendo. Without an adversary to cut down, there is no jikeiko (sparring), and with no greater community of dojo, there is no taikai (tournament) and no shiai (tournament fighting, the most intense mode of kendo).

Communicating one's intentions, motivations, goals, and availability for practice is vitally important to the mutually-dependent relationships and the ethos of the dojo.

Communication is the heart of writing, too. Writers must always have a community (even if it's just one friend) with which to communicate to create and refine, practice and publish. We value the process, especially feedback and revision; we workshop our writing. Professional writers have editors with built-in audiences to engage, as do academics who write within the structures and systems of higher education. Rhetors and compositionists are nothing without their audience, for what good is persuasion in solitude?

But what of the writer who is neither paid to write nor institutionally obligated? What of the hobbyist writer? The citizen writer? The aspiring writer? The searching writer, wandering, casting forth filament onto the page but not into the heart or mind of a reader? The internet can 
be daunting for its cold mechanical portal, but I can use the internet to find writing communities. And contribute. It all seems lost in a digital binary sea that breaks upon itself with evermore force. The sheer amount of writing put forth today is staggering. Why should I -- we -- write? To move an audience, or to satisfy our inner-selves, nothing else? Do I write for an audience, or do I write for myself? Am I on the path of shugyo, or am I here to win taikai. Do I want to impress, or is the impulse to impress merely a manifestation of insecurity, seeking affirmation. Does one unlock one's true potential by turning a key of indifference? Imperviousness to judgment as secret to success? To no longer seek approval from any source but oneself, and to hold oneself to a standard that cannot be imposed from without.

To reach this plane, writers and teachers of writing must communicate with ourselves, deeply and honestly. We must be aware of our purpose and act with intention, in all things, at all times, in every interaction, in every word. That is why I am making a renewed vow to teach and compose in the interest of democratic institutions and environmental activism. Rhetoric and composition is inspired by clarity when our self-awareness has dictated a purpose. This project has put my purpose into focus. Writing without purpose can be an entertaining and fruitful exercise, but any writer who hopes to move an audience -- let alone satisfy the soul -- must be clear-eyed about the mission, the purpose, the point. We need to know why we invent arguments and engage with experiences, so often painful. If clarity proves elusive during the journey, I hope at least to be aware that I do not know what or why, which is a purpose in and of itself: searching for what to fight for.

After all, that's the objective of shiai kendo: ippon, to strike soundly, to score a point, to move the audience -- to symbolically kill one's adversary. Isn't that the same objective of rhetoric and composition? To proffer points, to propel positions, to progress policy? The goal of shiai is to win, and it is to the "death." To win, one must clearly communicate with one's spirit, one's sword, and one's body, that the contest is over. That's just shia, though; in a typical kendo practice, the interpersonal communication is very much about appreciation just for the practice 
opportunity itself. I can communicate this more clearly to my students and to my audiences: that I appreciate them and depend upon them.

\section{Being Present: Demonstrations and Seminars}

Being a kendo player who seeks promotion involves creating a body of work and actively participating in demonstrations and seminars. In a kendo demonstration, we teach the public about our martial art. Participating in a demonstration shows pride in oneself and one's pursuits; it offers an audience an opportunity to learn -- and hopefully participate! Demonstrations involve active promotion, to a certain extent, to grow the community.

This can be true for so many other passions. What opportunities do rhetors and composers have to demonstrate and promote their passion to the public? We need to seek out -- create -- those opportunities. For instance, the spirit of teacher demonstrations during the National Writing Project fits right in with this priority of kendo.

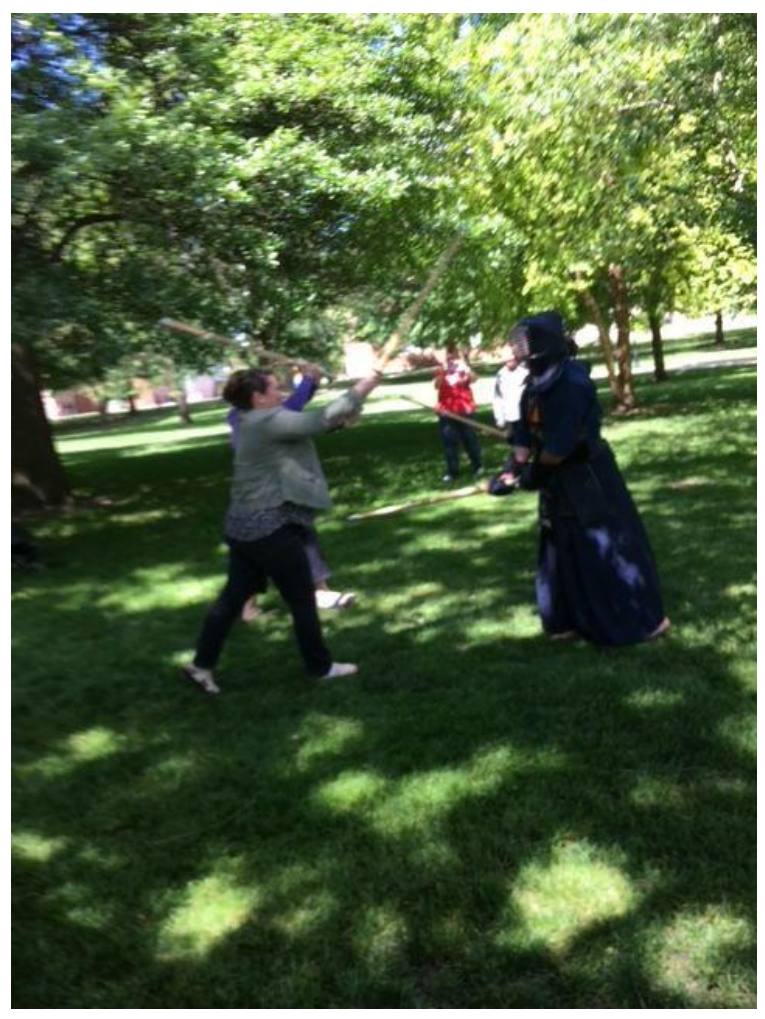

Figure 7:Illinois State Writing Project Kendo demo, Fell Arboretum (2018)

I've participated in three kendo demonstrations for Redbird anthropology students and once for the Illinois State Writing Project; multiple times at the BloNo cultural fest, both Miller Park and Brown Ballroom; at a nursing home on the eastside of town; at the Children's Discovery Museum for the closing of the Japanese exhibit; for a summer reading club at 
Washington High School after they read Samurai Rising (Turner, 2016); a handful of times at the Japanese cultural festival at the botanical gardens in St. Louis, which is by far the best demonstration around for atmosphere, gallery, and vibe! It's an amazing experience. A couple times we've dressed in ukata (traditional summertime, festival-going attire). I got way too into character one year, but it was so much fun. I had my old Japanese sensei and our kendo gang with us, so we were a formidable retinue taking in the gardens and swilling sake that night.

Giving these demonstrations out in the community strengthens one's credibility, common ground, and goodwill -- all vital elements of a worthy ethos. Community outreach and education -- that's what it is. Engagement. This is what a rhetor, writer, teacher must cultivate in practice. To plant seeds of curiosity and information, and offer opportunities to make connections and build relationships. I aim to expand my reach in the real world, connecting with people with whom I might continue to work, create, and progress. Making these relationships is a highly important element of project-based learning I intend to implement in my curriculum, which will bolster my classroom and our school's community: "Communities thrive when people have voice and when they're given opportunities to communicate with others" (Block 47). This is also supported by the samurai ethic: "The mind that looks into the principles of associating with people in a particular setting is a martial art as well" (Yagyu 12). The more I can participate in communities, the better. I cannot be content with my passivity. I must seize the opportunity.

Participating in seminars and competitions is highly encouraged and valued in kendo, too, especially if one hopes to compete at high levels of competition or attain a high-ranking. A seminar is when high-ranking sensei, often from Japan, travel to give intensive keiko. I've been to a seminar with Maeda-sensei from Florida, Don-san's teacher growing up -- (one-on-one instruction from hachi-dan!); with Sakamoto-sensei and Condon-san, down from Choyokan dojo in Chicago; to "Summer Camp" in STL last summer (which turned out to be the most punishing physical experience of my life, despite having to retire from playing collegiate football at Dartmouth because of mounting injuries my junior year); to a Detroit seminar with the Aiga 
brothers, one of whom is a former world champion; that one was memorable, not only for the high-level kendo instruction and my cramping forearm during promotion testing after a full day's worth of keiko, but because my wife permitted me to abandon her on Valentine's day weekend to drive 7 hours through what turned out to be a blizzard, and Beardy put Nobu's SUV in the ditch on the highway. We made it to Detroit, but it was -7 degrees when we arose at daybreak. But we journeyed to the seminar: to practice, to push ourselves, to represent our dojo, to be present.

Participating in seminars, workshops, ongoing education, professional development, and graduate programs as a student is beneficial and can be transformative for writers and composers. I must continue to engage these communities. I cannot allow myself to get hermetically sealed off in my classroom, secure in my tenure and a crystallized curriculum. I cannot simply accrue perfunctory PDUs for licensure renewal. I must ensure that I continue with IATE and NCTE. I have to attend the IATE conferences. I must continue with the Illinois State Writing Project. But I must also seek out non-professional communities of writers, especially local writing communities, like the Village All Write that l've been invited to participate in locally in Normal, IL, but have yet to engage with. I cannot grow as a teacher or writer without being active in these communities. If I do not get and stay engaged, I will surely "grow cold."

\section{Growing Through Pain}

St. Louis University, Summer 2018: I slowly kneel into seiza, hiding the searing pain behind a stoic mask. "Men to-rei!" Reaching behind my head to untie my men-himo, my right shoulder cramps, seizes, and spasms. I continue steely-eyed, unabated in my deception, my hope to blend in with the dozens of fellow kendoka. I remove my literal mask, my men-gane, yet the other mask remains, obscuring the truth of my horrendous physical state. The reality? I am internally buckling under the stillness and silence, the absolute cessation of activity in the gym that moments before had been a bubbling cauldron of swirling action and noisy aggression. 
"Mokuso!" I rest my cupped hands on my thighs, striving to focus on the negative space between my thumbs, to go inward into a void where I do not have the burden of this body, this husk; then, my foot cramps. The pain can only be embraced, held close. It passes, like a wave receding into an ocean of kendo pain that I have been navigating for these past ten years. The pain is tautening, taunting, teasing, and teaching. I am being repaid in kind by the kendo gods for claiming to desire a good kendo thrashing in the weeks leading up to Summer Camp. I had a debt and it came due. Be careful what you ask for.

All I can say about my Summer Camp experience - two and a half full days of kendo, from 6am onward -- is that, when all was said and done, I was at the absolute most painful physical moment of my life. I had wanted to be pushed to my limit, and I got it. I learned a lesson that could not have been gleaned from any other field but that of pain. I had been battered and rubbed raw, both physically and egotistically; I was humbled, laid low, shown the truth of my physical transience and impermanence. I stood at the edge, looked into the darkness, and stared at my mortality reflected in the abyss. I knew and accepted that day that I would cease to exist, hopefully old as an oak, but that when my time comes to cross over into non-being, I will welcome it with open arms, the embrace of infinity shepherding my suffering into nothingness.

That's how much I hurt. I only had one other semi-comparable kendo experience, and I bear the scar of that other fateful day at Choyokan, too, in my shot forearm that never really healed; it has since been diagnosed as "tennis elbow" and l'm managing it. Kendo, though, shouldn't be debilitatingly painful, like I experienced that day because of my lack of experience, preparation, planning, and precaution at Summer Camp, but it does hurt, objectively. Kendo has a high attrition rate that I attribute to the pain. I've seen big men who thought they were tough, who spent three months earning bogu, quit after only one full bore practice. To practice kendo, one must expect and embrace pain -- maybe even enjoy it, to a certain extent. 
So kendo physically hurts, at times, and it can sting emotionally, too, when one is completely destroyed by an opponent. Although it's not an official kendo motto of the AUSKF or anything, a favorite saying of my BNKC compatriots is, "Pain is good. Extreme pain?...

extremely good." Anyone who seriously practices kendo has an intimate relationship with pain. Paradoxically, I always -- always -- feel better walking out of the dojo than walking into the dojo. The physical exertion, unfettered mind, and getting whacked around for a couple hours results in healing, in strengthening. Kendo tempers flesh and spirit into hardened steel.

Is this what happens with my struggling or resistant writers in my classroom? Is writing too painful to willingly endure, let alone embrace? Writing can be painful, yet writing hurts while healing and strengthening, too: "Sharing experience through... writing moves us from passive suffering to active participation in healing" (Borrowman 143). We have to be vulnerable, honest, and open to criticism. That's why cultivating a spirit of community and camaraderie among my students is so vital, and collaborative project based-learning will nurture that togetherness.

In kendo, one is "criticized" by stinging men or debana-kote strikes during jigeiko. The sting is gone in an instant; the lessons, though, remain. The sting becomes comfort, the reassurance of pain, a loyal companion. Writing is similar. Criticism is awesome. If we seek a bold writing community that questions and challenges our ideas, along with a critical public audience, we strengthen our composition and rhetoric. Being subjected to critical evaluation is humbling yet empowering. Sharing one's ideas and meaning takes courage, and a powerful compositionist must bear the pain of criticism. Writing transforms pain. I am. I suffer. I write. I release. Writing can be painful, but the pain is a purge of the trauma.

Is writing more closely associated with pain or joy? Is that a meaningless question? Is it half and half, like yin-yang? Are pain and joy the same, identical, in direct correlation with one another? Perhaps it's the human in me, but l'll fight for joy via pain. To feel myself in an existential crisis of passivity as a composer and a teacher is quite painful, admitting it hurts, but working for solutions with and through my composition is lifting my spirits. I am in a much better 
headspace than when I began this project. Kendo does bring joy associated with strength and beauty, discipline and friendship. I relish the enjoyment of the endless toil of keiko.

Communities of writers can practice together in the same spirit as the kendoka: friends who spar with utmost vigor yet together celebrate the passing of time with another practice together, another chance to chase a strike that resonates, that pure strike when ki-ken-tai-ichi lock together in a moment: one beautiful motion that defies the eyes, stuns the reflexes with lightning flash. That's what I want for my teaching, and that's what I want for my future compositions: harmony of my ethos, my chosen modality and genre, and my action.

In kendo, that perfect men-strike disappears in an instant, but my composition can remain. And as a teacher? The impact of my efforts will abide longer and reverberate in more ways than I'll ever know. My teaching, when practiced with the ideal of ki-ken-tai-ichi, can be beautiful and powerful. One who moves never grows cold.

\section{Coda: Ichi and Integration}

Ki-ken-tai-ichi is synergistic. Unlocking the true power of each element is dependent upon harmony. The spirit, sword, and body -- the ethos, modality and genre, and action -- must be aligned. In kendo, when my ki-ken-tai is off, then I simply have an ugly practice or lose the match. In teaching and composing, however, failure might cost me the trust or attention of my students and audience, and my agency and voice would suffer. If I'm serious about fighting mistrust in our democratic institutions and environmental degradation, I must align the three elements to best engage and inspire my audience, whether students or readers.

In the preceding four chapters, I have discovered a personal crisis of confidence that is very much intersecting with American institutional and global environmental crises. I have broken down the elements of ki-ken-tai to better understand how I can strike effectively as a writer and a teacher of writing, and my path forward to more meaningful teaching of writing and participation in writing communities is coming into focus. I have declared my ideals as a citizen 
and consumer and my goals as a writer and teacher, so how will I begin actually realizing these aspirations? What can I do to integrate what l've learned through this writing process into my reality, my routines and practices? What does the harmony of ichi look like in my composition and in my writing classroom?

As a compositionist, I will continue to create after I earn my graduate degree. I will make composition habitual in my personal life, not for academic or professional obligations. Just like I routinely choose to practice kendo in the dojo, I will routinely dedicate precious personal time to composition. Although composition is so often solitary, I will prioritize joining a community. There is no way I could maintain quality kendo practice in solitude: I need fellow kendoka with whom to practice. I cannot lose sight of this with my composition. Whether I seek out and find in-person writing communities locally or if I'm participating in online spaces and forums, I need an audience and a void. I need to share and be ignored. I need criticism and encouragement. I need solidarity and opposition. None of this comes from solitude. I have to put myself out there. I will publish.

When I compose, I will make use of various genres and modalities. I will push myself beyond freewriting and journaling. I have ideas, and I will pursue them. I've never really had the courage to write much fiction, but I want to; I will. I will write short stories, screenplays, and one-act plays. I will blog about teaching and about kendo. I will write more creative non-fiction, utilizing images and recordings to bolster the power of my meaning and my voice.

I will represent who I am and what I stand for in my composition yet without stooping into the partisan fray that is degrading our public discourse today. How is that possible? I will generate compositions that document actions that reflect my professed values. I will share compositions that document my attempts to live as the responsible consumer and citizen I'm trying -- and often failing -- to be. I can compose and post about driving a fully-electric vehicle, attending a union meeting, composting my food waste responsibly, reading the local paper, installing solar panels on my roof, voting in a local election, shopping organic at my local food 
co-op, and eating vegetarian meals. I'm also feeling inspired to volunteer more, and I want to document those experiences with writing, images, and videos. (I'm afraid I might use a hashtag for the first time.) I will actively seek out opportunities to do my small part, share who I am, and hopefully find an audience. This path is before me, and it will take a concerted effort to contribute in a way that I can feel good about, but I want to make that effort.

I do not, however, want to curate an idealized version of myself online, only composing and sharing in a potentially self-aggrandizing way. It's important that I document, share, and discuss my shortcomings and struggles, too. I'm far from perfect, and I still have much to learn, experience, and understand. I'll document actions not only to more fully be who I want to be but to redeem and atone for my previous and ongoing selfishness, pessimism, and reticence. I will sacrifice time and energy for hope, and I will strive to contribute to a better tomorrow by documenting and sharing those actions. I'm done with being a passive consumer; I will be an active creator.

What I do not want is to directly demean those with whom I disagree or don't see eye to eye on social, political, or cultural issues. I don't want to participate with good intentions only to succumb to the vitriol of our fallen discourse infecting my ethos and rhetoric. I don't want to fight people; I will fight our problems. I hope to help us heal by composing in good faith and contributing to a sustainable future with actions, then words. I'm not surprised that a well-known Gandhi quote is apt: "You have to be the change you want to see in the world."

I've been despondent. I've been sad. As a parent of three young sons, I'm worried about the future on so many levels. However, the writing-to-learn that l've experienced by holding kendo up to composition has revealed that I can no longer wallow in hopelessness or decry a lack of personal agency to make a positive impact on the future. I have to participate in activities that build who I hope to be, then I must document those activities, and share them publicly. This is how I can pursue ki-ken-tai-ichi in my personal composition moving forward. I will fight to be who I want to become with my actions, and I will use my voice to position myself 
as an agent of change -- if only to effect change in myself. Because how can I fight for the future, if I do not fight for myself and my identity as a consumer, a teacher, a parent, a partner, an American, and a human being alive on Earth in 2021?

As a teacher of writing, I will improve my ki-ken-tai-ichi for the sake of my students. Being a teacher is an opportunity and a responsibility as a public servant. The primary upshot for my teaching from this thesis is that I will strengthen the fighting spirit of my classroom; In my classroom, we will spar with serious issues. I will fight for a spirit of good-faith inquiry. Clearly, one way to achieve this is by embracing current events, rather than hiding from them. I cannot turn back the clock to offer my students meaningful discussion of the past presidential election and the insurrection at the Capitol, but I can use that guilt l've discovered by facing the next controversial issue with courage and offering my students the space and respect they deserve to delve into these issues that really matter. I will no longer succumb to fear of conflict or debate.

By embracing the conflict that comes with current events, I will inherently be building the rei-ho of my classroom. Students will feel respected with a classroom that invites them to grapple with the issues that will have massive impacts on their futures. The fact of the matter is that I have a sacred duty as a teacher in an American public high school to empower my students with the curiosity and critical thinking skills, along with the literacy tools necessary to be productive, responsible members of our democracy. Another highly valuable revelation from this project is my lack of trust in myself to remain calm and constructive with my students when an issue arises that I feel strongly about. This awareness, in and of itself, will be beneficial to my teaching, as I now know that I will remain tranquil when these conflicts arise. I cannot continue to deprive my students because I lack confidence in my temper. When something does arise that I know will get me potentially too fired up, I need to be honest with my students about it -- while continuing to allow them to inquire, discuss, and debate. This thesis has uncovered a paradox that I must embrace: to allow my students to engage serious issues that pertain to our future, issues that I worry deeply about, I must detach emotionally. If I let the 
spectre of a misinformed or hostile student deter me from inviting all my additional students to engage these issues, then I'm making the mistake that has mired so much of our collective discourse and communal action: ignoring the issues that most matter because we can't even agree to debate respectfully about it. I will keep my composure and embrace the debates, even when odious opinions and ideas are proffered, for the sake of my students' education.

Project-based learning will be essential to my work as an educator moving forward. I began this process to an extent before writing this thesis, but I now have a much better vision of what my classroom can be when inquiry and creativity are at the heart of my student-centered classroom. I already did away with quizzes and tests last year, but the creative opportunities I implemented instead were not even close to as well-developed and meaningful as they will be with revision. I will better utilize multimodal tools and various genres, especially for publication to mantle student voices. The projects I offer my students must have a call to action and an avenue of publication. I will offer projects rooted in the spirit of inquiry, anchored in multimodal composition and texts for learning and expression, and reliant upon students being active creators, and I will achieve ki-ken-tai-ichi in my classroom. This ippon, however, will not be shinpon raising a red or white flag at taikai, it will be engaged young people being better informed about their society and their world, fighting for their future by writing. Students are the ultimate judge of a teacher, and I hope to earn their respect and to spur them to action as civic-minded Americans and environmentally-conscious stewards of planet Earth.

Finally, I ask myself: How can I improve my kendo practice with what I know of composition and teaching? The answer is laying in plain sight at the heart of this thesis itself: writing-to-learn. I undertook this thesis without knowing where it would lead. I knew that these two pillars of my identity, literacy and kendo, would have much to say if given space to converse. What I did not know was how painful it would prove to be, ultimately confronting a crisis that I had been repressing. Now it's out, and I will be the better composer and teacher for it. 
What have I been repressing in my kendo practice? What have I ignored or overlooked? What bad habits have I formed? What good habits have I neglected? How can I have an even better understanding of rei-ho? How am I actively working to overcome the four sicknesses? What should be my focus? These are questions I intend to answer by writing-to-learn. I've never kept a regular kendo journal, but I intend, from this day forth, to make it part of my kendo routine. I will have a dedicated journal in which I will document my questions and reflections after each practice. My writing will surely digress from kendo onto other topics, too, and that's fine; however, I will write-to-learn about my shugyo, further intertwining these two threads that hold together the fabric of my identity. Kendo, composition, and teaching will continue to be forged into flashing steel within me. 


\section{REFERENCES}

Borrowman, Shane., eds. Trauma And The Teaching Of Writing. Albany, NY : State University Of New York Press, 2005.

Block, Joshua. Teaching for a Living Democracy: Project-based Learning in the English and History Classroom. Teachers College Press, 2020.

Coe, Richard. "Defining Rhetoric -- and Us"; Journal of Advanced Composition, Vol. 10, No.1 (1990), pp. 39-52.

Clavell, James. Shogun. Delacorte Press, 1975.

Crowley, Sharon \& Debra Hawhee. (2012). Ancient Rhetorics for Contemporary Students (5th edition). Boston: Pearson.

Elbow, Peter. Writing With Power: Techniques For Mastering The Writing Process. New York : Oxford University Press, 1981. Print.

Elbow, Peter. Writing Without Teachers. New York: Oxford University Press, 1998. Print.

Haddix, Marcelle, et al. "'Y'all Always Told Me to Stand up for What I Believe In': 21st-Century Youth Writers, Activism, and Civic Engagement." Journal of Adolescent \& Adult Literacy, vol. 59, no. 3, Nov. 2015, pp. 261-265.

Inoue, Asao B. Labor-Based Grading Contracts: Building Equity and Inclusion in the Compassionate Writing Classroom. The WAC Clearinghouse; University Press of Colorado, 2019.

Lieberman and Wood. Inside the National Writing Project: Connecting Network Learning and Classroom Teaching. Teachers College Press, 2002.

McCall, George. kenshi24/7.com.

Menken, Steph, et al. An Introduction to Interdisciplinary Research: Theory and Practice; Amsterdam University Press: 2016.

Nitobe, Inazo. Bushido: The Soul of Japan, A Classic Essay on Samurai Ethics. New York: Kodansha USA; 2012.

Poulkas, John. "Toward a Sophistic Definition of Rhetoric"; Philosophy \& Rhetoric, Vol. 16, No. 1 (1983), pp. 35-48; Penn State University Press. 
Repko, Allen. Interdisciplinary Research: Process and Theory. Los Angeles: Sage Publications; 2008.

Salmon, Geoff. Kendo, Inherited Wisdom and Personal Reflections. Rethink Press; 2013.

Salmon, Geoff. kendo-info.net

Soho, Takuan (1573-1645). The Unfettered Mind: Writings from a Zen Master to a Master Swordsman. New York: Shambhala; 2012.

Selfe, Cyntha, et al. Multimodal Composition: Resources for Teachers. Hampton Press, 2007.

Yamamoto, Tsunetomo, 1659-1719. Hagakure : The Book of the Samurai. Tokyo: New York: Kodansha International; distributed in the United States by Harper \& Row, 1979.

Yoshikawa, Eiji. Musashi. Kodansha International, 1981. 


\section{APPENDIX: PERSONAL PHOTOGRAPHS FROM MY KENDO PRACTICE}

1. Nobu-san and I demonstrating kendo at the Japanese Cultural festival in 2015.

Nobu-san is demonstrating the nito (2-sword) style. Nobu-san is addressing the gallery, so he is not wearing mengane. We had to trust our practice and preparation to avoid a whack to the head! Nobu-san got a huge laugh at the end of this demonstration by revealing the most effective technique when faced with a sword fight: dropping his shinai and running in the other direction!

2. Nobu-san speaking at a kendo demonstration at the Bloomington-Normal cultural festival in 2011. I am sitting in seiza, participating in my very first demonstration less than a year into my kendo practice.

3. Here are the three katana displayed prominently in my home. The top is shinken: the live blade. This blade is dangerous, so I treat it with great care (and keep it out of reach of my sons). The middle sword is my iaito, which does not have a sharp cutting-edge. liato are practice swords, with which a mistake can be made without an ensuing injury. The bottom sword (in its sword bag) is my wife's iaito. We love practicing iaido together.

4. These are my three different swords used for kendo practice. The top two swords are bokken (wooden swords): odachi and kodachi. These swords are used for kata, which are choreographed routines with two partners: uchidachi and shodachi. My bokken were handmade by a friend, Dan Walther, an ISU alum and BNKC icon who now lives in Japan, where he continues his kendo practice. The bottom sword is shinai, the primary sword used in kendo. It's made of four bamboo slats held together with nakayui (leather rigging). The bamboo slats are flexible, so our skulls and bones are always stronger than the shinai.

5. Our kakejiku at the BNKC. It overlooks every single practice at the dojo. It's message is now deeply ingrained in my ethos: one who moves never grows cold. It's amazing what great shape it's in, despite being handled before and after every practice. 
6. Here's a group shot after a BNKC practice. We often take photos when joined by a guest or to mark a special occasion or milestone. We took this picture to document the last practice with a member before he departed to work and practice kendo in Shanghai for a year. That's me on the far right.

7. A teacher-leader from the Illinois State Writing Project hits me with a men strike at my kendo demonstration during the Summer Institute in 2018. It's always fun to practice and demonstrate kendo outdoors, and the arboretum at ISU offered a beautiful backdrop for getting whacked in the head by my fellow teachers! 